NBER WORKING PAPER SERIES

\title{
DO CASH TRANSFERS IMPROVE BIRTH OUTCOMES? EVIDENCE FROM MATCHED VITAL STATISTICS, SOCIAL SECURITY AND PROGRAM DATA
}

\author{
Verónica Amarante \\ Marco Manacorda \\ Edward Miguel \\ Andrea Vigorito \\ Working Paper 17690 \\ http://www.nber.org/papers/w17690
}

\author{
NATIONAL BUREAU OF ECONOMIC RESEARCH \\ 1050 Massachusetts Avenue \\ Cambridge, MA 02138 \\ December 2011
}

(]

[

We are grateful to Uruguay's former Minister and Deputy Minister of Social Development, Marina Arismendi and Ana Olivera, respectively, and their staff, in particular Marianela Bertoni, Juan Pablo Labat and Lauro Meléndez at the Monitoring and Evaluation Unit, for their invaluable support, and to other officials at the Ministry of Social Development, the Ministry of Public Health, and the Social Security Administration (Banco de Prevision Social) for their help with the data and for clarifying many features of program design and implementation. An incomplete earlier working paper version was produced under the aegis of the IADB research project "Improving Early Childhood Development in Latin America and the Caribbean". We are grateful to the IADB for financial support and to the research project coordinators, Jere Behrman, Cesar Bouillon, Julian Cristia, Florencia Lopez Boo and Hugo Nopo, for comments on the earlier version. We are also grateful to Janet Currie, Josh Graff-Zivin, and Mindy Marks and to seminar participants at U.C. Riverside, U.C. San Diego, Universidad Autònoma de Barcelona, the NBER Summer Institute 2011, Princeton, LSE, the IADB, the World Bank, Universidad de la Plata, Essex, and LACEA 2010 for useful comments. Mariana Zerpa and Guillermo Alves provided excellent research assistance. The opinions expressed in this paper do not necessarily reflect the views of the Government of Uruguay, the National Bureau of Economic Research, or the IADB. All errors remain our own.

NBER working papers are circulated for discussion and comment purposes. They have not been peerreviewed or been subject to the review by the NBER Board of Directors that accompanies official NBER publications.

(C) 2011 by Verónica Amarante, Marco Manacorda, Edward Miguel, and Andrea Vigorito. All rights reserved. Short sections of text, not to exceed two paragraphs, may be quoted without explicit permission provided that full credit, including $\odot$ notice, is given to the source. 
Do Cash Transfers Improve Birth Outcomes? Evidence from Matched Vital Statistics, Social Security and Program Data

Verónica Amarante, Marco Manacorda, Edward Miguel, and Andrea Vigorito

NBER Working Paper No. 17690

December 2011

JEL No. I38,J13,J88

\section{$\underline{\text { ABSTRACT }}$}

There is limited empirical evidence on whether unrestricted cash social assistance to poor pregnant women improves children's birth outcomes. Using program administrative micro-data matched to longitudinal vital statistics on the universe of births in Uruguay, we estimate that participation in a generous cash transfer program led to a sizeable $15 \%$ reduction in the incidence of low birthweight. Improvements in mother nutrition and a fall in labor supply, out-of-wedlock births and mother's smoking all appear to contribute to the effect. We conclude that, by improving child health, unrestricted unconditional cash transfers may help break the cycle of intergenerational poverty.

Verónica Amarante

Universidad de la Republica

Joaquin Requena 1375

Montevideo 11200

Uruguay

vero@iecon.ccee.edu.uy

Marco Manacorda

Department of Economics

Queen Mary University of London

CEP - London School of Economics

Houghton Street

London WC2A $2 \mathrm{AE}$

UK

m.manacorda@1se.ac.uk
Edward Miguel

Department of Economics

University of California, Berkeley

530 Evans Hall \#3880

Berkeley, CA 94720

and NBER

emiguel@econ.berkeley.edu

Andrea Vigorito

Instituto de Economia

Facultad de Ciencias Economicas

Universidad de la Republica

Joaquin Requena 1375

Montevideo 11200

Uruguay

andrea@iecon.ccee.edu.uy 


\section{Introduction}

This paper estimates the impact of in utero exposure to a cash social assistance program - the Uruguayan Plan de Atención Nacional a la Emergencia Social (PANES), which provided households with a sizeable transfer - on children's early health outcomes. An unusually rich dataset of matched micro-data from vital statistics, hospital data, social security and program administrative records allows us to exploit multiple sources of quasi-experimental variation in the receipt of cash assistance, allowing us to estimate the causal effect of additional disposable income during pregnancy on birth outcomes and investigate a range of underlying mechanisms.

Children of poor parents are at disproportionate risk of ending up in poverty themselves (Black and Devereux 2011). This is partly due to their poorer health, which both affects the acquisition of other dimensions of human capital (e.g., education, Miguel and Kremer 2004) and can directly impact economic outcomes later in life (Case, Fertig and Paxson 2005). There is limited empirical evidence, though, on whether cash social assistance to poor parents improves children's health outcomes, potentially helping to break the cycle of intergenerational poverty. In their comprehensive discussion of the determinants and consequences of early human capital development, Almond and Currie (2011a, p. 1368) conclude that "research has shown little evidence of positive effects of cash welfare on children".

Improvements in household financial resources brought about by social assistance could, in principle, increase children's wellbeing through better nutrition, sanitation and health care (Case 2000, Case, Lubotsky and Paxson 2005). The reduction in maternal stress brought about by welfare transfers might also positively impact birth outcomes. However, there is evidence that offsetting behavioral responses might also be at work, including negative parental labor supply responses to welfare transfers (Moffitt 2000, Hoynes 1996, Hoynes and Schanzenbach 2011). Even in the absence of such responses, poor parents might favor current consumption over investments in their children's human capital due to credit constrains (Card 1999), myopia or self-control problems (Banerjee and Mullainathan 2010), imperfect altruism (Udry 2004), intergenerational commitment problems (Baland and Robinson 2000), or limited information about the technology of, or returns to, their children's human capital accumulation (Jensen 2010). Social assistance could even potentially increase the consumption of certain "bads" (such as cigarettes, drugs or alcohol) that negatively affect birth outcomes, could lead to family break-up (Moffitt 1998) with possibly detrimental effects on child wellbeing, or could increase the fraction of children born in poor health 
by creating incentives for women with limited financial resources to boost their fertility (Currie and Moretti 2008). ${ }^{1}$ Ultimately, whether cash transfers to poor parents affect children's early health outcomes positively, negatively or at all remains an open empirical question.

In this paper, we focus on the effect of cash social assistance on a measure of early life health: low birthweight, defined by the World Health Organization as weight under 2,500 g (or roughly 5.5 pounds). This is a widely available measure, and a considerable body of research shows that it is a major determinant of both short-run child health outcomes and long-run life outcomes, including height, IQ, earnings, education and even birthweight of the next generation (see Almond, Chay and Lee 2005, Almond and Currie 2011a, Almond, Hoynes and Schanzenbach 2011b, Behrman and Rosenzweig 2004, Black, Devereux and Salvanes 2007, Currie and Hyson 1999, Currie and Moretti 2007, Currie 2009, Royer 2009).

Early interventions, and in particular those in utero, have the potential to be particularly cost-effective since their benefits extend over a longer time span, due to potential complementarities with other inputs, and to the possibility that they permanently affect the path of individual physiological and cognitive development (Heckman 1995, 2000). Targeting children in utero, though, is particularly challenging as pregnancy status is often ascertained with some delay, and this might be particularly true for women whose children are most likely to benefit from early interventions. With a few notable exceptions, evidence on the effect of in utero exposure to cash transfers on birth outcomes, and in particular on low birthweight, is limited. This paucity of credible evidence results from the lack of both adequate micro-data as well as convincing sources of exogenous variation in cash transfers. Another important open question is the stage of pregnancy at which such programs are most effective. The main channels of impact are also poorly understood, largely due to data limitations.

This paper contributes to filling these gaps. Beyond specifically focusing on a social assistance program whose major component was an unrestricted cash transfer, the contribution of this paper lies in the data set that we have assembled and the opportunities that it offers for econometric identification of both program effects and mechanisms. We link multiple sources of

\footnotetext{
${ }^{1}$ Indeed, it is precisely because of some of these undesirable effects that in-kind (e.g., food stamps) or conditional social assistance is often advocated. As long as households would consume less of the good if provided with an equivalent monetary transfer, and the goods and services transferred are not fungible for money, in-kind transfers have the potential to increase the consumption of such goods (see Currie and Gahvari 2008). The conditionalities attached to many recent cash transfer programs in less developed countries are similarly meant to induce specific desirable behaviors among participants (Fiszbein and Schady 2009).
} 
administrative micro-data to build a monthly longitudinal data set spanning five years of individual women's pregnancy and birth outcomes, clinical histories and circumstances surrounding the pregnancy and birth; PANES program transfers; and socio-demographic characteristics and labor market participation, earnings, and the receipt of other public benefits for the universe of female program applicants of child-bearing age (approximately 157,000 women).

To our knowledge, this paper represents the first effort to link the universe of vital statistics data to social assistance transfer program data at the level of individual beneficiaries. In contrast, most existing studies (reviewed below) use either survey data with self-reported birth outcomes, program receipt and income, or they rely on geographically aggregated program enrollment and vital statistics data. Because of the aggregate nature of the data used in many related studies, estimation of program effects typically relies on differential variation in program eligibility across geographic areas and/or demographic groups. An obvious drawback of such approaches is the difficulty of ruling out unobserved trends in outcomes that are correlated with eligibility, possibly inducing omitted variable bias. In contrast, our data allows us to exploit variation in individual eligibility induced by exact program assignment rules and timing, leading to arguably more credible identification of causal program effects.

Indeed, as a way to corroborate our findings, we obtain similar program impact estimates with multiple quasi-experimental econometric identification strategies. We first employ a difference-in-differences (DD) estimator that compares the incidence of low birthweight among the infants of program beneficiaries versus non-beneficiaries born before and after the PANES program was launched. Because households entered the program at different points in time during its national roll-out, this allows us to control for any aggregate trends in low birthweight. We then exploit alternative sources of variation in certain subsamples. We first restrict the analysis to mothers with more than one child and include maternal fixed effects (FE). This approach relies on comparison of siblings who were and were not exposed to the program in utero, allowing us to control for any unobserved time-invariant heterogeneity across mothers. Second, since PANES program eligibility depended on a discontinuous function of a baseline predicted income score, we next use an additional source of variation in the data. We restrict attention to children whose households are in the neighborhood of the program eligibility threshold and compare "barely eligible" to "barely ineligible" children using a regression discontinuity (RD) design. 
To preview our results, we find that the program led to a roughly 15 percent decrease in the incidence of low birthweight (1.5 percentage points on baseline incidence of 10 percent), using all three econometric approaches. In two years, the program completely closed the pre-existing gap in low birthweight incidence between the (worse off) mothers eligible for the cash transfer program and the (slightly better off) mothers who applied but did not qualify. The analysis shows that providing unrestricted cash social assistance to the poor improved early child health outcomes.

The dataset also allows us to investigate a larger set of potential mechanisms than most other studies, including household labor supply, family structure, residential mobility, effects that operate through risky behaviors (e.g., smoking), health care utilization, insurance coverage, other government benefits, as well as fertility. ${ }^{2}$ These other channels could theoretically either offset or reinforce the positive main effect of the program on infants' wellbeing due to improved maternal nutrition and health brought about by increased financial resources during pregnancy.

We document behavioral changes along a variety of hypothesized margins that together contribute to the overall reduction in low birthweight. First, we find that PANES beneficiary mothers show weight gains during pregnancy, consistent with the view that improved maternal nutrition is a key channel. We also find a sharp reduction in smoking during pregnancy in the treated group, which (speculatively) may be due to a reduction in stress brought about by the cash assistance, and a sizeable reduction in out-of-wedlock births, which may also affect health outcomes. Consistent with standard theory in labor economics, the PANES transfer led to a reduction in maternal labor supply, though effects are modest in magnitude, and despite these offsetting effects the program still led to sizeable increases in net household income. The reduction in maternal labor supply could also have benefited child health by reducing mothers' stress levels.

The paper is organized as follows. Section 2 reviews the literature on the determinants of birthweight and in particular on the effect of government transfer programs. Section 3 provides institutional information about the program. Section 4 describes the data, section 5 discusses multiple identification strategies and presents the main results, while section 6 investigates the mechanisms. Section 7 presents a speculative rate of return analysis that suggests program transfers may be an attractive policy option, and the final section concludes.

\footnotetext{
${ }^{2}$ Using data on the universe of births also allows us to circumvent problems of endogenous reporting that might arise in other settings, while administrative information on both program receipt and child birthweight should reduce the measurement error that is thought to affect survey self-reports, reducing bias and increasing statistical precision.
} 


\section{Determinants of low birthweight and the role of income assistance}

A large body of research points to maternal nutrition and both physical and mental health during pregnancy as major determinants of birth outcomes in general, and low birthweight in particular. Poor health, smoking and undernutrition are all known to lead to intrauterine growth retardation, as well as possibly to shorter gestational length and prematurity (itself mechanically linked to low birthweight). ${ }^{3}$ There is also a consensus that prenatal care, especially in the first trimester of pregnancy, is effective at improving infant health through the opportunities it provides for early diagnosis and for education about best practices (Kramer 1987, Alexander and Korenbrot 1995).

Recent attempts to link birthweight to household socioeconomic status and to economic characteristics that correlate with the above risk factors have generated mixed results. There is some evidence that higher maternal education improves infant outcomes, arguably due to its effect on maternal behavior (for example, by reducing smoking), increased earnings, improved marriage outcomes and reduced fertility (Currie and Moretti 2003), although other work does not corroborate this result (McCrary and Royer 2010). There is limited evidence that mother's disposable income during pregnancy affects low birthweight, though an effect may be present for specific subpopulations, such as mothers who were themselves born with low birthweight (Conley and Bennett 2000, 2001). Aggregate macroeconomic conditions also appear to matter, with different studies again reaching divergent conclusions, with some pointing to increases in low birthweight during economic downturns and others to decreases (Dehejia and Lleras-Muney 2004, Bozzoli and Quintan-Domeque 2010). Interpretation of these aggregate results is complicated by compositional differences in the types of mothers giving birth throughout the business cycle.

More direct - and relevant (for this paper) - evidence comes from studies that analyze government welfare and transfer programs. A body of evidence, largely from the United States, focuses on programs that aim to improve the nutritional and health status of pregnant women.

\footnotetext{
${ }^{3}$ Maternal under-nutrition, anemia, malaria, infections, pre-eclampsia and cigarette smoking are typically identified as important risk factors for intrauterine growth retardation (Kramer 1987). Almond and Mazumder (2011) show that maternal fasting has negative effects on birthweight. Other risk factors include environmental pollution (Currie and Schmieder 2009, Currie, Neidell and Schmieder 2009, Currie and Walker 2010), exposure to violence (Camacho 2008, Aizer, Stroud and Buka 2009, Aizer 2010) and mother's labor supply, possibly due to stress (del Bono et al 2008). Kramer (1987) identifies genital tract infections, employment and physical activity, smoking behavior, stress, general morbidity and prenatal care as the main predictors of gestational length. Recent evidence also points to the role of mother's nutrition (Murtaugh and Weingart 1995), anthropometric measures, genetic factors, and stress (Clausson et al. 2008, Ruiz et al. 2008, Buss et al. 2009).
} 
Bitler and Currie (2004) and Hoynes, Page and Huff Stevens (2010) study the Special Supplemental Nutrition Program for Women, Infants and Children (WIC), which provides food and nutritional advice to pregnant women, and both find that the program reduces the incidence of low birthweight infants. One channel through which WIC appears to have an effect is via greater prenatal care utilization. Additional evidence comes from the conditional cash transfers literature. Barber and Gertler (2008) evaluate the impact of the Mexican Progresa/Oportunidades program on birthweight, exploiting the random initial assignment of the program across communities. In a sample of 840 women, they find a very large reduction in the incidence of low birthweight as selfreported in a survey (of 4.5 percentage points on a base of around 10\%) which they attribute to better quality prenatal care and the adoption of better health behaviors.

Other studies focus on in-kind social assistance, with mixed results. Almond, Hoynes and Schanzenbach (2011a, 2011b) find sizeable and precisely estimated effects of the U.S. Food Stamps program on low birthweight, as well as on health outcomes later in life. They estimate that exposure to the program in the last trimester of pregnancy reduces the incidence of low birthweight by 7 to 8 percent for whites and 5 to 12 percent for blacks. Yet Currie and Moretti (2008) do not find this pattern for California, a fact that they explain with increased fertility (due to the program) among a subset of mothers more likely to have worse birth outcomes.

Evidence on the effects of unrestricted and unconditional cash transfers is scant, and one should not automatically presume that cash and in-kind transfers have the same effect on birth outcomes. Currie and Cole (1993) focus on participation in the Aid to Families with Dependent Children (AFDC) program. Despite the fact that AFDC mothers were also more likely to receive Medicaid, Food Stamps, and housing subsidies, all of which could improve birth outcomes (e.g., see Currie and Gruber 1996 on Medicaid), they find no significant effects on low birthweight.

One of the most convincing and relevant papers is Hoynes, Miller and Simon (2011), who focus on the effect of the U.S. Earned Income Tax Credit (EITC) on birthweight. Exploiting the differential effects of subsequent EITC reforms on children born at different parities, as well as changes in state-level program generosity over time, they use a difference-in-differences approach with grouped data to show that the EITC program led to a sizeable average reduction of $7 \%$ in the incidence of low birthweight, with particularly pronounced effects among less educated and ethnic minority mothers. Although the authors discuss various channels that affect birth outcomes, their data does not allow them to directly investigate these channels empirically. 


\section{The PANES Program}

The Uruguayan Plan de Atención Nacional a la Emergencia Social (PANES) was a temporary social assistance program targeted to the poorest 10 percent of households in the country, and was implemented between April 2005 and December 2007. ${ }^{4}$ The program was devised by the centerleft government that took office in March 2005 following the severe economic crisis of the early 2000's, when per capita income fell by more than 10 percent, unemployment reached its highest level in twenty years, and the poverty rate doubled. The crisis laid bare the weakness of the existing social safety net, which was largely focused on transfers to the elderly population, a fact reflected in marked differences in poverty incidence by age, with nearly 50 percent of children aged zero to five living in poverty compared to just 8 percent for the over sixty-five population (UNDP 2008). Despite a rapid deterioration in living standards during the crisis, Uruguay remained a good performer in terms of infant mortality, birthweight and health care utilization relative to other Latin American countries, with levels not dissimilar to the U.S. (appendix Table A1). ${ }^{5}$

\subsection{Eligibility}

Following an initial program application phase (which mainly occurred in April and May 2005), households were visited by Ministry of Social Development personnel and administered a detailed baseline survey. Because of the large volume of applications and the time and resources needed to administer the survey, these household visits took place throughout most of the second half of 2005, sometimes with considerable delay from the date of original application (see Figure 1 and especially appendix Figure A1).

The baseline survey allowed program officials to calculate a predicted income score based on a linear combination of a large number of household socioeconomic characteristics, which in turn determined program eligibility. ${ }^{6}$ Households with a predicted income score below a

\footnotetext{
${ }^{4}$ The program was replaced in January 2008 by a new system of family allowances accompanied by a health care reform and an overhaul of the tax system, together called the Plan de Equidad.

${ }^{5}$ Uruguay is a middle-income country with annual GDP per capita of US\$13,189 (in 2006 PPP), and is home to 3.3 million individuals. This highly urbanized country experienced rapid economic growth in the early $20^{\text {th }}$ century, and was among the first countries in the region with universal primary education and a generous old-age pension system. Uruguay is still among the most developed Latin American countries according to the UNDP Human Development Index, with relatively high life expectancy and schooling indicators.

${ }^{6}$ The eligibility score, which was devised by researchers at the University of the Republic in Montevideo (Amarante et al., 2005), including some of the authors of this paper, was based on a probit model of the likelihood of being below a
} 
predetermined level were assigned to the program. The program was not specifically targeted to pregnant women, nor was child-bearing an eligibility criterion.

Of the 188,671 applicant households (with around 700,000 individuals), roughly 102,000 households eventually became program beneficiaries, or approximately 10 percent of all Uruguayan households (and 14 percent of the national population). The total cost of the program was approximately US\$250 million, i.e. US\$2,500 per beneficiary household, and on an annual basis, program spending was equivalent to $0.4 \%$ of GDP.

\subsection{Program components}

PANES eligible households were entitled to a monthly cash transfer whose value was originally set at US\$56 (UY\$1,360 at the 2005 exchange rate, equivalent to approximately US\$103 in PPP terms) independent of household size, and was later adjusted for inflation. This amounted to approximately 50 percent of average pre-program household self-reported income for recipient households (and nearly 100\% of pre-treatment income among those households who gave birth during the period of analysis). The majority of households first received the cash transfer during 2005, although due to the delays in administering the baseline survey, there was considerable variation in the timing of first payments even among the earliest applicants (appendix Figure A1).

Successful applicants were entitled to the transfer for the duration of the program until December 2007, provided their formal sector earnings remained below a predetermined level (approximately US\$50 per month per capita). ${ }^{7}$ Although continued receipt of transfers was also, in principle, conditioned on regular health checks for pregnant women and children (plus children's

critical per capita income level, using a highly saturated function of household variables, including: the presence of children from different age groups, public employees in the household, pensioners in the household, average years of education among individuals over age 18 and its square, indicators for age of the household head, residential overcrowding, whether the household was renting its residence, toilet facilities and an index of durables ownership. The model was estimated using the 2003 and 2004 National Household Survey (Encuesta Continua de Hogares). The resulting coefficient estimates were used to predict a poverty score for each applicant household using PANES baseline survey data. Neither the enumerators nor households were ever informed about the exact variables that entered into the score, the weights attached to them, or the program eligibility threshold, easing concerns about its manipulation (which we further assess in appendix Figure A2). The eligibility thresholds were allowed to vary across five national regions. Although official government documents used a predicted poverty score, in this paper we use a predicted income score, which is simply -1 times the poverty score. This simplifies presentation, as households with higher values of the score are better off, but it obviously makes no difference to the analysis.

${ }^{7}$ The social security administration performed periodic checks on PANES beneficiaries' records to enforce this condition. As shown below, there is evidence that a non-trivial fraction of beneficiaries stopped receiving the transfer before the end of the program, typically because of their failure to satisfy this income conditionality. 
school attendance), ${ }^{8}$ due to limited resources and coordination across government ministries, these conditionalities were never enforced, an issue later publicly acknowledged by the government and confirmed by the fact that very few beneficiary households knew of their existence: in a 2007 survey, only $12 \%$ of beneficiary households were aware of the official prenatal visit condition.

A second, smaller program component only launched midway through the program, in mid-2006, was an electronic food card, whose monthly value varied approximately between US\$13 and US\$30 (UY\$300 to 800), or between one fourth and one half of the value of the income transfer, depending on household size and demographic structure. ${ }^{9}$

\section{Data}

The analysis brings together several individual-level data sets (Figure 1). PANES administrative records provide information from the initial survey visit for both successful ("eligible”) and unsuccessful ("ineligible”) applicants on baseline household demographic characteristics, housing conditions, income, labor market participation, schooling, durable asset ownership, and the household's exact predicted income score used to determine eligibility. These data also contain the unique national identification number (cédula) for all household members, and allow us to identify individuals belonging to the same household. For successful applicants, the data also provide monthly information on the amount of the cash transfer and, if applicable, the food card.

PANES program data are matched to vital statistics natality micro-data that provide information on all registered live births in the country (Instituto Nacional de Estadística 2009). Vital statistics come from certificates completed by physicians at the time of birth and they contain information on birthweight, some parental characteristics, and the reproductive history of the mother. At 98 percent, the fraction of registered births in Uruguay is the highest in Latin America (UNICEF 2005, Cabella and Peri 2005, Duryea, Olgiati and Stone 2006). Vital statistics data are available every year from 2003 to 2007, and so also include the period before the start of PANES in April 2005 (Figure 1). These data also include some information on prenatal care utilization that is collected as the pregnancy progresses. The confidential version of the data used in this paper includes the mother's cédula, and this allows us to link the vital statistics to program data.

\footnotetext{
${ }^{8}$ In particular, for pregnant women, the program officially prescribed monthly prenatal visits (and weekly visits from week 36 on) and three mandatory ultrasounds.

${ }^{9}$ See Appendix B for a detailed discussion of these and other aspects of the program.
} 
Additional information on maternal health during pregnancy is provided by the SIP (in Spanish, Sistema de Informático Perinatal, or prenatal information system) database, devised by the Latin American Centre of Perinatology and collected in multiple Latin American countries (Fescina et al. 2007). This dataset collects detailed pregnancy information, including mothers' weight at the time of both the first and the last pre-natal visits, as well as smoking in the first trimester of pregnancy. One drawback of the data, though, is that there is incomplete coverage during the program period (full national coverage was only achieved in 2009), although during the 2003 to 2007 period its coverage increases. As a result, SIP data are available for a subset of roughly one third of the births in our main analysis. Fortunately, we show below that coverage rates are identical among PANES eligible and ineligible mothers.

Finally, we also link program and vital statistics data to Social Security records for all members of PANES applicant households, again using the unique cédula individual number. These data contain monthly information on income from formal employment (for both employees and the self-employed, excluding the non-civilian labor force, i.e., the police and military), and all public transfers, including pensions, unemployment benefits, disability and a small pre-existing child allowance (that had negligible transfers relative to PANES). Social security data are available starting in March 2004, and thus are available for more than a year before the launch of PANES.

The data are summarized in Table 1. The top three panels report averages for the period January 2003 to March 2005 before the start of the program, while the bottom panel reports information for April 2005 to December 2007. We report means for three groups of mothers: those who applied and eventually became eligible for PANES (column 1), those who unsuccessfully applied to the program (column 2), and those who did not apply (column 3). Roughly speaking, these three groups correspond to increasingly higher levels of income and socio-economic status.

The data show a clear gradient in birthweight across groups (rows 1 and 2). While among PANES eligible households the fraction of births below 2,500 grams is 10.2 percent, among nonapplicant households it is 8.4 percent, and for ineligible applicants it lies in between, at 9.3 percent. There is also clear evidence that PANES eligible mothers had the fewest prenatal visits at baseline (6.5 versus 7.5 for ineligible applicants and 8.3 for non-applicant mothers, row 4, although the average number of visits is still considerable) and that they had their first prenatal visit later in the pregnancy (in week 17 compared to week 16 for ineligible applicants and week 14 for nonapplicants, row 5). PANES eligible mothers were also more likely to live in areas with lower 
average birthweight (row 9), more likely to give birth in public health centers (row 11) and less likely to be privately insured (row 12). ${ }^{10}$

There is additional information on mothers' reproductive history and parents' sociodemographic characteristics, and as expected PANES eligibility status is negatively correlated with mother's education (row 13) and positively correlated with the number of previous pregnancies (row 14). PANES eligible mothers are less likely to be married to the father's child (row 15). ${ }^{11}$ PANES fathers also display lower levels of education (row 17).

Unsurprisingly, PANES eligible mothers are also less likely to report being employed at the time of birth (row 18), have lower formal sector earnings during pregnancy (row 19) and belong to households with less labor and non-labor income (rows 20 to 22). Total household monthly income (including earnings and benefits) in the first two trimesters of pregnancy is UY\$1,113 (in April 2005 UY\$) for PANES mothers, and around twice as much for ineligible applicant mothers. Although this figure is likely to underestimate true income levels among these households, as it excludes earnings from informal employment and any non-governmental transfers, it remains very low at approximately US\$45 per mother (or US\$90 PPP adjusted).

In the pre-program period, the SIP data show that a large share of mothers smoked, at 31\% in the PANES eligible group and 25\% among ineligibles (row 26), and as expected, these mothers displayed lower average body weight (rows 27 and 28). The finding of more low-weight mothers in poor households is consistent with some under-nutrition among these mothers at baseline.

Panel D in Table 2 reports data for the program period. It is notable that the gap in low birthweight between eligible and ineligible applicant mothers completely closes during the program period, with the two applicant groups of mothers (columns 1 and 2) showing a low birthweight incidence of 9.1 percent (row 29). Around 97 percent of PANES eligible mothers received the program at some point during the period (row 30), although only around 55 percent received it sometime in the first two trimesters of pregnancy (row 31). This gap is due both to the staggered incorporation of households into the program (discussed above) as well as to some beneficiaries losing eligibility due to their eventual failure to meet the income means test. Although a small share of ineligible mothers also eventually received transfers, initial eligibility remains a

\footnotetext{
${ }^{10}$ A universal, de facto free, health system of relatively poor quality coexists in Uruguay with mandated employerprovided private insurance. In practice, nearly all formal workers have access to private insurance.

${ }^{11}$ This fraction is quite high in Uruguay as a whole, with nearly $60 \%$ of children born out-of-wedlock.
} 
strong predictor of program receipt. ${ }^{12}$ The gap in total household income between eligible and ineligible households closes substantially (row 39), largely due to the transfer (row 32).

\section{Econometric analysis}

The discussion of the program implies that for a child to have been exposed to the PANES program in utero two conditions must be satisfied: first, the mother must be a program beneficiary, and second, the child must have been born after the mother entered the program. This immediately suggests a difference-in-differences (DD) strategy for estimating program effects that relies on a comparison of birth outcomes for children born to program eligible versus ineligible mothers, both before and after program expansion. The basic DD regression model is then:

$$
Y_{i m t}=\alpha+\beta^{D D} T_{i m t}+\gamma 1\left(N_{m}<0\right)+d_{t}+d_{p}+u_{i m t}
$$

where $t$ is the month of conception of child $i$ of mother $m, Y$ is the birth outcome variable (e.g., low birthweight), and $T$ is an indicator for treatment. The terms $d_{t}$ and $d_{p}$ are, respectively, indicators for month of conception and month at which the household received its first PANES cash payment. An indicator for the household predicted income score, $N_{m}$, falling in the eligible range $\left(N_{m}<0\right)$ is also included in all specifications.

Equation 1 exploits the staggered entry into the program across mothers (appendix Figure A1), and compares the difference in birthweight between a treated child (one born after her mother was enrolled in the program) and an untreated child to the difference between two children with identical dates of conception who were either both treated or both untreated. By conditioning on date of conception indicators, equation 1 controls for general trends in the incidence of low birthweight due to, for instance, secular improvement in health care quality or living standards, while conditioning on $d_{p}$ controls for the possibility that birthweight outcomes might vary across mothers with different program entry timing, perhaps due to the selective nature of application timing or in the length of application processing.

\footnotetext{
${ }^{12}$ A related paper (Manacorda et al. 2011) presents evidence of nearly perfect compliance with the initial eligibility rules. The program enrollment data used in that paper, though, only refer to the period through March 2006, plus it excludes homeless households, who were always incorporated into PANES regardless of their predicted income score. In the present paper, we find evidence of slightly laxer enforcement of the eligibility rules in the final six months of the program (namely, the second semester of 2007).
} 
As our data contain detailed information on weeks of gestation, we are able to measure program exposure in terms of time elapsed since conception as opposed to the time before birth (as is customary in most existing studies). This subtle distinction is important and allows us to circumvent the potential selection bias that would arise if program participation affected gestational length, where the latter is correlated with birth outcomes. A related estimation issue is that children with shorter gestational lengths will mechanically have a shorter period of program "exposure", potentially biasing program impact estimates. To address this, in the analysis below we define treatment as a child's mother having started to receive PANES payments at any point up to six months after conception, regardless of the timing of the birth. For children with normal gestational length, and in the absence of program drop-outs, this measure is equivalent to in utero exposure during the entire last trimester, which is typically regarded as a critical period for improvements in birthweight and length brought about by income and nutritional programs (as discussed below).

A further issue relates to program drop-out driven by the income conditionality attached to the program, which over time disqualifies a non-trivial fraction of beneficiary households. A household economic shock during pregnancy, e.g., finding a job, might affect both birth outcomes and household income, and hence program participation, again potentially biasing program impact estimates. A related issue is imperfect enforcement of the eligibility rules, which we showed above affects a moderate proportion of originally ineligible households. If such receipt among ineligible households is correlated with their birth outcomes, i.e., if mothers who know how to "work the system" to eventually get PANES benefits are also more determined in accessing prenatal care, this could bias estimates. To address these issues, we instrument the PANES treatment term with an indicator that takes on a value of one for PANES eligible women's pregnancies in which the date of the first cash payment occurs sometime before the end of the second trimester.

Two further issues are worth mentioning. First, fertility might be endogenous to program eligibility and cash transfer receipt. This might be the case because the program affects the likelihood of conception (via changing access to contraception, or evolving fertility preferences), or of successfully completing a pregnancy through selective fetal survival or abortion. ${ }^{13}$ Endogenous fertility choices could lead to bias if the types of mothers whose fertility is affected have different

\footnotetext{
${ }^{13}$ Although abortion is illegal in Uruguay other than when the life of the mother is at risk, it is widely practiced. The Centro Internacional de Investigación e Información para la Paz (CIIIP) estimates a rate of voluntary abortion of $38.5 \%$ (for the year 2000). The comparable rate in the U.S. is much lower, on the order of $20 \%$ of pregnancies.
} 
risk of low birthweight. A second issue is selective program entry times, if the incidence of low birthweight is correlated with this timing. Because of the longitudinal nature of the data, we can address both of these concerns by further refining the difference-in-differences strategy with the inclusion of mother fixed effects (FE), $d_{m}$, in equation 2, rather than the $d_{p}$ terms. This allows us to control for unobserved time-invariant mother heterogeneity to address any concerns about compositional changes in the population of mothers.

$$
Y_{i m t}=\alpha+\beta^{D D} T_{i m t}+d_{t}+d_{m}+u_{i m t}
$$

Given program assignment rules, we obtain an alternative estimate of program impacts by comparing outcomes of "barely eligible" and "barely ineligible" children in the neighborhood of the program eligibility threshold based on a regression discontinuity (RD) design. Following Card and Lee (2008), we estimate the following model on data from the program period:

$$
Y_{i m t}=\alpha+\beta^{R D} T_{i m t}+f_{1}\left(N_{m}\right)+1\left(N_{m}<0\right) f_{2}\left(N_{m}\right)+u_{i m t},
$$

where $f_{1}\left(N_{m}\right)$ and $f_{2}\left(N_{m}\right)$ are two parametric polynomials in the normalized predicted income score for mother $m\left(N_{m}\right)$ such that $f_{l}(0)=f_{2}(0)=0$, and $1($.) is an indicator function. We again use 2SLS, where we instrument $T_{i m t}$ with $1\left(N_{m}<0\right)$. This approach allows us to address the variation in eligibility associated with different application and entry dates.

Both of these alternative identification strategies (FE and RD) only make use of a subset of the data, and because of this they could generate somewhat less precise estimates. For this reason most of the analysis focuses on the full sample DD estimates. However, we show below that coefficient estimates and, in most cases, significance levels are almost unchanged with the DD, FE and RD approaches.

\subsection{Main results}

Figure 2 presents the incidence of low birthweight as a function of the time to and since the first PANES payment, restricting attention to mothers who were (eventually) eligible and treated. Each point corresponds to a three month period (and thus the numbers on horizontal axis correspond to years), and the data are standardized such that zero corresponds to births with positive but less than one full trimester of in utero exposure, meaning that the mother started receiving the program sometime during the third trimester of pregnancy. There is a visible drop in the incidence of low 
birthweight among children with positive program exposure relative to those born before the mother entered the program (with negative exposure). There is an additional drop among those whose mother entered the program in the second semester of pregnancy (who had at least one full trimester of exposure). Beyond that, the incidence of low birthweight remains roughly constant (with some apparent sampling variability), implying that there is no additional gain for mothers entering the program even earlier in the pregnancy or before conception.

The right hand side panel reports (on the vertical axis) the fraction of children treated, i.e., those whose mother received a PANES payment starting sometime before the third trimester. Program participation is positively associated with in utero exposure, as expected, with an increase on the order of 90 percentage points in the first year, although program participation falls slightly at longer exposures due to some dropping-out.

Table 2 presents 2SLS estimates of the effect of program exposure based on the DD specification in equation 1 . Each row presents results for a different dependent variable, and standard errors are clustered at the mother level throughout. Although equation 1 could be estimated using only PANES eligible mothers (see below), including non-PANES mothers (unsuccessful applicants) increases precision and so they are included in most of the analysis. Consistent with Figure 2 and Table 1, the estimates in rows 1 and 2 show that low birthweight incidence falls by around 1.5 percentage points, while mean child birthweight increases by 23 to 30 grams (or almost exactly one ounce) following program exposure, with both estimates significant at $95 \%$ confidence. Estimates are virtually unchanged when additional demographic controls and controls for the month of the baseline survey visit are included in column 2.

Figure 3 reports the implied proportional change in the fraction of newborns below any given weight level, together with the associated 95 percent confidence interval; these coefficients are estimated based on a series of regressions similar to those in row 1, column 2 (of Table 2). Program exposure significantly reduces the incidence of a range of birthweights below 3,000 g, with effects again on the order of 10 to 15 percent, although estimates lose statistical significance for weights below approximately 2,300 $\mathrm{g}$ due to the drop in observations in this range.

In utero program exposure marginally increases gestation length (by 0.07 weeks or roughly half a day, an increase of just 0.2 percent on average gestational length of 38.5 weeks); we return to this result below. There are no apparent impacts on premature births (row 4). 


\subsection{Effects by length of in utero exposure}

A question in the existing literature is whether social assistance is more effective at improving birth outcomes at particular stages of pregnancy. For example, a finding that transfers in the first trimester of pregnancy mattered most would make it more difficult to design policies to improve child birth outcomes in practice since many pregnancies are not detected at an early stage, and detection may be a greater concern for mothers at higher risk of having low birthweight children.

The data allow us to estimate the differential impacts of the program at different time points during pregnancy. Table 2, row 6 reports OLS estimates from a regression of low birthweight on indicators for different lengths of PANES exposure (i.e., less than one trimester, one full trimester, two full trimesters, or three full trimesters and more, the latter meaning that the mother entered the program before conceiving). Coefficients are expressed as differences relative to zero exposure, i.e., to children who were not eligible for the program at any time during the pregnancy. For comparison, row 7 reports reduced form estimates that pool as "treated" those eligible starting in either the first or second trimester. Consistent with Almond, Hoynes and Schanzenbach (2011a), and with the evidence in Figure 2 we find a significant reduction in the incidence of low birthweight, on the order of -1 to -2 percentage points, from entering the program at any point during the first or second trimester, and this is consistent with full program exposure during the third trimester mattering most. Moreover, conditional on exposure during the entire third trimester, we cannot reject the hypothesis that the effect of PANES exposure is the same for those who began receiving transfers in the second trimester, the first trimester, and before conception at conventional confidence levels (not shown).

Finally, the first stage relationship is presented in row 8 of Panel $\mathrm{B}$, and implies that program eligibility increases program participation by 86 percentage points, suggesting a high degree of compliance with assigned program status.

\subsection{Alternative identification strategies}

Table 3 reports additional specifications intended to test the robustness of the results. For brevity, we focus on specifications with additional controls (as in column 2 of Table 2), although the results also hold without controls (not shown). Row 1 presents estimates including mother fixed effects. Despite cutting the sample size in half, including mother fixed effects leads to an estimate $(-0.018)$ 
that is nearly identical to the baseline estimate and is significant at $95 \%$ confidence, suggesting that unobserved time-invariant individual heterogeneity is not generating a spurious regression result.

While the baseline difference-in-differences specifications in Table 2 include both PANES eligible and ineligible mothers (with $\mathrm{N}=68,858$ ), the point estimate computed only among the sample of PANES eligible mothers in row 2 of Table $3(\mathrm{~N}=48,891)$, and which exploits changes in their eligibility over time, is nearly identical at -0.016 and significant at $95 \%$.

As an alternative to exploiting the variation among eligible mothers, we next exploit the variation between eligible and ineligible mothers. Figure 4 presents the proportion of low weight births as a function of the predicted income score in the narrow range from -0.1 to +0.1 (denoting plus or minus 10 percentage points in the likelihood that the household qualifies as PANES eligible based on its characteristics as measured in the baseline survey) near the program eligibility threshold, both during (Panel A) and before (Panel B) the program, as well as showing the proportion of births in treated households (Panel C). Linear and non-parametric regression curves estimated on both sides of the threshold (and the confidence intervals on the linear estimates) are also presented. The data indicate a drop in the incidence of low birthweight at the eligibility threshold during the program period on the order of 1.5 percentage points (Panel A). There is no discontinuity in the proportion of low weight births in the pre-program period (Panel B), consistent with the key identifying assumption that, absent PANES, low birthweight would be a continuous function of the predicted income score. Program participation is highly discontinuous at the predicted income score threshold, with a jump of approximately 70 percentage points, as dictated by program assignment rules. ${ }^{14}$ The natural conclusion from Figure 4 is that PANES program participation significantly reduces the incidence of low birthweight.

This finding is confirmed by the "fuzzy" regression discontinuity estimates in rows 3 to 5 of Table 3. The sample here is restricted to pregnancies that occurred after the program started. ${ }^{15}$

\footnotetext{
${ }^{14}$ Appendix Figure A2 Panel A shows that the distribution of the predicted income score is smooth around the program eligibility threshold, suggesting an absence of manipulation in the score (McCrary 2008). Panel B shows that the distribution of birthweights is smooth around the low birthweight cut-off (2,500g), further indication of data quality. ${ }^{15}$ Specifically, cconsistent with the difference-in-differences estimates, for eligible mothers we define treated pregnancies as those that started no more than six months before the receipt of first program payment. For ineligible mothers (for whom there is no comparable date of first payment) we consider pregnancies that started no earlier than five months before the baseline visit in the sample; we choose five months since the median difference between the date of first payment and the date of the baseline survey is one month, thus preserving the six month "lead time" we use throughout in defining program treatment. Estimates are nearly identical when using the timing of the baseline
} 
Except for indicator variables for month of entry into the program, the model includes the same regressors as in column 2 of Table 2, and the treatment variable is instrumented with an indicator equal to one for mothers with a predicted income score that makes them eligible for PANES (namely, those with negative predicted scores, as the threshold is normalized to zero). The point estimate in row 3 that uses all available observations is similar to the baseline estimate, at -0.013 , and significant at 95\% confidence. The estimate in row 4 that restricts the analysis to observations in the narrow range near the eligibility threshold, from -0.1 to +0.1 , is virtually unchanged $(-0.014)$ and significant at 90\% confidence; standard errors increase here with the substantially smaller restricted sample, which falls by more than half. We further estimate the model with a linear polynomial control in the predicted income score (in row 5), and the point estimate remains similar $(-0.014)$ although it is no longer statistically significant, which is not surprising since, by further saturating the model, the econometric identification becomes highly localized and there are effectively fewer observations driving the estimates.

To address the possibility that program entry dates could be correlated with individual trends in low birthweight, in row 6 we allow the instrumental variable for treatment to be an indicator that takes on a value of one for all pregnancies among eligible mothers that started no earlier than January 2005, regardless of the actual date of the respondent's entry into the program. This classifies all children of PANES-eligible mothers born in the second trimester of 2005 or later as program participants. This is a conservative assumption that introduces some measurement error in actual program participation dates but eliminates any bias due to selective entry timing. The coefficient estimate on PANES participation is once again similar, at -0.020, and significant at 95\% confidence, easing concerns about bias due to endogenous entry times.

\section{Mechanisms underlying the reduction in low birthweight}

The richness of the dataset allows us to investigate many potential behavioral channels that could be behind the finding that the program reduced the incidence of low birthweight, including those related to changes in income and labor supply (section 6.1), gestational length, medical care and mothers' health during pregnancy (6.2), family structure (6.3), cash versus in-kind transfers (6.4), and fertility choices and selective child survival (6.5). Multiple mechanisms appear to contribute to 
the overall reduction in low birthweight, and there is no evidence of the adverse behavioral changes that have been hypothesized.

\subsection{Income and labor supply}

Standard theory in labor economics predicts that welfare programs will tend to reduce labor supply, due to both a substitution effect (induced by means-tested benefits) and an income effect (see Moffitt 2002 for a discussion of the evidence). Such labor supply responses would dampen the increase in expenditures generated by welfare transfers. However, the effect of this change on birth outcomes is ambiguous, since by allowing pregnant women to withdraw from the labor market, welfare transfers could reduce physical and psychological stress, improving birth outcomes.

Panel A of Table 4 estimates program effects on household and mother socioeconomic measures during the pregnancy. The dependent variable in row 1 is the average value of the PANES cash transfer over the first six months following conception. The estimated coefficient is UY\$1040, or approximately US\$40 at the 2005 exchange rate. This number is roughly 30 percent lower than the program transfer (UY\$1,360), consistent with the imperfect compliance with program assignment documented above.

Row 2 reports the effect of eligibility for the food card. Eligibility is associated with in-kind food card transfers during pregnancy of UY\$191 per month, or US\$7. As with income transfers, this is substantially below what in-kind transfers would have been with full take-up, given both imperfect compliance and the fact that the food card component was rolled-out mid-program (appendix Figure A1, panel D). Row 3 shows there was no significant increase (or decrease) in the total amount of other government benefits received as a result of program treatment.

Rows 4 and 5 specifically examine mother earnings and household earnings, respectively. There is evidence that PANES mothers and their households earned somewhat less in the formal labor market than their non-eligible counterparts, but the differences are relatively small (at UY\$40 and 175 for mothers and households, respectively, or approximately US\$2 and 8). Consistent with this finding, row 6 shows there was a moderate fall of 1.3 percentage points in mother's labor supply during pregnancy, as reported in the birth records. Despite these negative labor supply effects, program eligible households experience a large increase in total household income, by UY\$968 per month (row 7), where this figure includes all sources of formal sector income and transfers as recorded in the Social Security database during the first six months after conception. 
As a conservative counterfactual, using the fact that total household income between July 2006 and December 2007 (when the program had completely rolled out) among unsuccessful applicants was roughly UY\$3,650 (or just over US\$140 per month), this implies that the program increased total household income by at least 25 percent. Recall that pre-program total household income among PANES eligible households was UY\$1,113 per month, but this is a questionable "base" figure for a counterfactual given mean reversion, and the recovering Uruguayan economy during this period.

We also investigate whether residential mobility increased due to the transfer, and specifically whether it led households to move to neighborhoods with better average health outcomes. There is no indication (row 8) of an improvement in the average health in households' residential area (as proxied by pre-PANES average birthweight) among program households.

\subsection{Gestational length, medical care, and mothers' health during pregnancy}

Table 2 showed that the program led to a small increase in gestational length. A different question is the extent to which greater gestational length can account for the program's reduction in low birthweight incidence. In row 7 of Table 3 we re-estimate equation 1 restricting the sample to nonpremature births (defined as 38 or more weeks): the estimate of -0.009 is significant at $99 \%$ confidence, although somewhat smaller than the baseline result, suggesting that greater gestational may be playing some role. We also report the effect of the program on the probability of being in the bottom decile of the birthweight distribution conditional on gestational length (in row 5 of Table 2): there is a sharp reduction in being in the bottom decile, with a drop of 1.6 percentage points, suggesting that the effect of the program on low birthweight also works through boosting intrauterine growth per unit of time in utero rather than only through gestational length.

The fall in low birthweight is accompanied by an increase in the number of prenatal visits overall, and especially in the third trimester (rows 9 through 12 of Table 4), which again could partially be the result of greater gestational length. The effect on the total number of visits is relatively small though, at 0.144 , i.e. an increase of just 2 percent relative to baseline. Moreover, there is no evidence that the week of first visit (row 13) or the total number of visits in the first trimester (row 10) - which are considered crucial for the detection and treatment of pregnancy risk factors - improve. Taken together, these patterns imply that improvements in prenatal care are unlikely to be driving the low birthweight effects unless there was a sharp improvement in the quality of care received at each visit. 
While we have no direct information on the quality of prenatal care, there is little evidence of improvements in the quality of medical care at birth and delivery for PANES beneficiary mothers. Neither the proportion of births assisted by a doctor (row 14), nor the fraction of births in public hospitals, which are generally of lower quality (row 15), nor the average (pre-PANES) birthweight at the mother's health center (row 16) were affected by program participation. ${ }^{16}$

Despite the lack of clear changes in prenatal or delivery care, a number of maternal health and nutrition measures do improve during pregnancy. Most importantly, mother's weight is higher among eligible mothers and it improves significantly during pregnancy. We find that mothers are $0.5 \mathrm{~kg}$ (approximately one pound) heavier than untreated mothers (row 18), although this effect is not significant at conventional levels. By the final prenatal visit, the average weight gain for treated mothers is $0.95 \mathrm{~kg}$ (approximately two pounds, row 19). These findings are consistent with the hypothesis that the higher household income generated by the PANES transfer led to improved maternal nutrition, and thus greater child growth in utero. ${ }^{17}$

A second notable health outcome in the SIP dataset is the sharp reduction in maternal smoking during the first trimester, with a drop of 3.2 percentage points (row 20, significant at 95\% confidence), on a base of roughly 31\% in the pre-program period. Smoking is strongly linked to low birthweight in the medical literature (Kramer 1987). While any explanation for this drop in smoking is necessarily speculative, a plausible factor is falling stress in PANES beneficiary households as a result of their improved economic circumstances. ${ }^{18}$

\subsection{Family structure}

One theoretical possibility is that welfare transfers could reduce the incentives for marriage, either because of the conditionalities associated with program receipt (i.e., if the income conditionality includes the husband's income) or the additional financial resources they make available to women. Growing up in a "broken" family, in turn, could possibly have negative consequences on children's wellbeing through material, social or psychological channels. Although the existing evidence from the U.S. points to zero or only modest negative effects of welfare transfers on single

\footnotetext{
${ }^{16}$ PANES did not involve the creation of new health centres or any other health supply intervention.

${ }^{17}$ As expected, there is no "impact" on treated mothers' height (point estimate $0.43 \mathrm{~cm}$, s.e. 0.34).

${ }^{18}$ Banerjee and Mullainathan (2010) discuss why "temptation goods" like cigarettes might constitute a particularly large share of consumption among the poor.
} 
motherhood and marital stability, economic theory yields ambiguous predictions on the sign of these effects (Bitler, Gelbach, Hoynes and Zavodny 2004).

Rows 21 and 22 of Table 4 report that PANES led to a large and statistically significant reduction in the proportion of children born to unmarried parents, as well as in the proportion without a father named on the birth certificate. Contrary to what is often presumed, welfare transfers lead to a moderate increase in martial stability, with a drop of 2.1 percentage points (on a base of 80\%) in out-of-wedlock births. To the extent that intact marriages and the presence of the father have positive impacts on mother and child, this could partly explain the program effects on low birthweight. The increase in marriage rates and identified fathers could be due to multiple factors, including the possibility that the income transfer led to greater relationship stability (perhaps by reducing stress), that it made the mother a more attractive marriage partner, or that the improvement in economic circumstances simply allowed the couple to feel secure enough to get married. In any case, there is no evidence of the adverse behavioral responses with respect to marriage that have been hypothesized.

\subsection{Cash versus in-kind transfers}

To disentangle the roles of cash versus in-kind transfers, Table 3 reports results from regressions that exploit the fact that the food card was only rolled out starting in the second half of 2006 (appendix Figure A1) and that the date of entry into this program component did not coincide with the first payment of the cash transfer. Row 8 restricts the sample to births that occurred before June 2006, i.e., before any food cards were distributed, while row 9 explicitly controls for the date of first receipt of a food card payment, to assess if it has any additional effect. In both instances, the effect of the cash transfer on low birthweight is nearly identical to the baseline specification and statistically significant at 95 and 99\% confidence, respectively, indicating that the cash transfer alone leads to a reduction in low birthweight incidence. The additional receipt of the food card on top of the income transfer does not affect low birthweight incidence (although the point estimates are imprecisely estimated, not shown).

\subsection{Fertility choices and selective fetal survival}

Another possibility is that the program affected fertility or fetal survival among mothers at risk of having low birthweight children. Cash transfers could theoretically lead to either higher or lower 
fertility: if children are a normal good, the cash transfer could increase fertility (Becker 1960), although it might also lead to increased investment in child quality while reducing overall fertility. ${ }^{19}$ The existing empirical evidence is mixed (Moffitt 1998).

As a first check on fertility impacts, row 10 of Table 3 presents estimated program impacts on low birthweight among the subsample of pregnancies that started before the first PANES payment was made. This sample restriction should largely control for endogenous fertility responses since these pregnancies reflect choices made before exposure to the program (unless individuals could accurately predict the exact timing of their incorporation into the program, which seems highly unlikely given the uncertainties surrounding this new program, which was the first of its kind in Uruguay). Results are similar (at -0.019) to the baseline estimates and significant at 95\% confidence, suggesting that bias due to endogenous fertility is unlikely to explain the main results.

We next investigate fertility patterns directly. Using the universe of PANES applicant women of child-bearing age (12 to 50 years old), we create a quarterly panel that spans the period January 2003 to December 2008. For each trimester, we construct an indicator variable equal to one if the woman gave birth and zero otherwise. Overall, we have information on approximately 157,000 women over 24 quarters, with more than 3 million individual-quarter observations, who have an average monthly fertility rate of 0.73 percent

The leading challenge in estimating the fertility response to PANES is the fact that program eligibility depended in part on the number of children in the household at the time of the baseline survey, implying that mothers who gave birth just before the survey were considerably more likely to be eligible than otherwise identical mothers giving birth just afterwards. ${ }^{20}$ This eligibility rule coupled with negative state dependence in childbearing (i.e., the probability of giving birth to a child today conditional on a child having been born in the previous nine months is basically zero), mechanically leads to a fall in observed fertility among eligible mothers after the launch of the program, which might be erroneously considered a causal program effect. This is simply regression to the mean, which arises in many other contexts, for example, in analyses of the effect of job training on wages (Ashenfelter 1978, Card and Sullivan 1988). Consistent with this mechanism,

\footnotetext{
${ }^{19}$ See Becker and Lewis (1973). An additional effect might arise if program generosity is conditioned on the number of children (e.g., Stecklov et al 2006). However, PANES consisted of a fixed transfer per household.

${ }^{20}$ This is confirmed by Panel A in appendix Figure A3, which shows a clear discontinuity in the probability of household PANES treatment as a function of the child's date of birth.
} 
the difference in fertility rates between PANES eligible and ineligible applicants (Figure 5) displays a sharp drop precisely at the time of the baseline survey used to determine program eligibility. ${ }^{21}$

An immediate way to correct for any bias induced by this compositional effect is to reweight observations for PANES ineligible mothers so that the distribution of pre-program characteristics is the same as for eligible mothers. We use past fertility (births between January 2003 and the baseline survey) and mothers' observable characteristics in the reweighting. ${ }^{22}$ Differences in fertility rates between eligible and ineligible women after reweighting are displayed in Panel B of Figure 5, where by construction, pre-program differences are zero. Visually, there appears to be a slight increase in fertility among PANES-eligible women during the program.

Estimation results are reported in Table 4, panel E, where a fertility indicator is the dependent variable (in the 2SLS specification). Consistent with the graphical evidence in Figure 5, fertility increases slightly among eligible mothers after the program begins: the point estimate implies a significant rise in fertility of 0.0013 (row 23), and with pre-program average monthly fertility among eligible mothers of around 0.008 , this is equivalent to roughly a 16 percent rise in fertility. As a bound, in the extreme and unrealistic case where this rise in fertility was entirely driven by individuals with exactly zero probability of giving birth to low weight children, this change in fertility could account for the roughly 16 percent drop in the incidence of low birthweight documented above. However, under more realistic assumptions, the increase in fertility would explain only a small fraction of the overall effect.

Because any change in fertility induced by the program would take at least nine months to materialize, an arguably cleaner test is provided by restricting attention to the first year of the program. Row 24 of Table 4 restricts the analysis to births that took place within one year of the baseline survey, and yields an effect in fertility of just 0.0002, implying a rise of around 3 percent, though this small effect is not significant at conventional levels. Yet the estimated program impact

\footnotetext{
${ }^{21}$ A similar result is obtained if we plot fertility rates as a function of time to and since the first payment for PANES eligible households only, similar to Figure 2. This series is plotted in appendix Figure A3, panel B. Panel C reports fertility rates as a function of time to and since baseline (as in Figure 5), plotted separately by eligibility status. Unsurprisingly, among eligible households the data show a similar pattern to that in Panel B, while, among unsuccessful applicant households, there is no clear time pattern. That the compositional differences between eligible and ineligible households is driving the results in Figure 5 is confirmed in panels D to F, which successively plot fertility rates for eligible and ineligible applicants separately by the number of children born between January 2003 and the administration of the baseline survey (namely, 0,1 , or 2 or more children). Conditional on households' past fertility history, fertility patterns during the program appear nearly identical for eligible and ineligible applicants.

${ }^{22}$ In practice, we define cells based on mother's age (in years), mother's years of education, month of baseline survey, and number of pregnancies at different lags (1-3 months, 4-6 months etc.) from the baseline survey.
} 
on the incidence of low birthweight during exactly the same time period (in row 11 of Table 4) is again virtually identical to the baseline estimate at -0.012 , providing another piece of evidence that endogenous fertility changes cannot explain the main birthweight result.

\subsection{Treatment effect heterogeneity}

We next explored some obvious dimensions of maternal heterogeneity to determine if the effects of cash transfers are more pronounced among particular subgroups. We first find that the reduction in low birth weight is particularly large among the roughly one fifth of our sample who are teen mothers, with a drop of 2.9 percentage points (relative to 1.6 percentage points among non-teen mothers, Table 3, rows 12 and 13) and among married mothers, with a drop of 2.8 percentage points (versus 1.3 points for unmarried mothers, rows 14 and 15). However, these differences are not significant at conventional confidence levels (with p-values of 0.37 and 0.19 , respectively).

Finally, since the magnitude of the income transfer was fixed regardless of household size, households with fewer members effectively received a larger per capita transfer than larger households. We divide the sample of mothers into those in smaller households (three or fewer members) and larger ones (at least four members) to test if this led to larger gains in smaller households but find no evidence that it did, with identical estimated reductions of 1.8 percentage points in both groups (rows 16 and 17). There are many possible explanations, including the fact that there is limited variation in household size in the sample overall (given low fertility rates in Uruguay, even among the poor). Imperfect income pooling among adults in the household would also serve to dampen the effect of household size on the magnitude of the program treatment effect.

\section{Estimating a lower bound on the internal rate of return}

A standard way to assess the attractiveness of an investment is to compute its internal rate of return (IRR). This section carries out a simple exercise that yields a bound on the IRR for the PANES program. There are a range of plausible but hard to quantify benefits of child health investments, including the individual utility gains of simply feeling better by avoiding illness, as well as the cost savings in early life medical care and hospital costs of the kind documented in Almond, Chay and Lee (2005). The benefits to the parents of the children and other household members, as well any social benefits (due, for example, to reduced health care utilization) are also disregarded entirely below. We adopt a narrower and highly conservative approach, focusing only on the estimated 
future wage benefits of the intervention when the children who benefited reach adulthood. Thus the IRR estimates below are clearly lower bounds on the true social returns.

Since the PANES program was only carried out during 2005 to 2007 and the children born have not yet reached adulthood, we obviously do not have actual measures of their adult labor market outcomes, and need to make assumptions about the likely returns to reducing low birthweight. We use the estimated reduction in low birthweight from Table 2 (row 1, column 2) in the current paper, namely, a 1.7 percentage point reduction for children of mothers who received the transfer throughout most of their pregnancy. Following Currie and Moretti's (2007) U.S. study (in their Table 6), we further assume that low birthweight reduces adult earnings by 2.6 percent, although returns are plausibly higher in a poor Uruguayan population, again making this a conservative assumption. We assume that individuals work from 18 to 65 years of age with earnings at the level of Uruguayan per capita income, and that the country's average per capita income growth rate of 2.3 percent during 1989-2009 continues over the coming decades. ${ }^{23}$ In terms of costs, we assume the social cost of the program is the deadweight loss incurred on the tax revenue raised to fund the PANES transfers, which we assume is 20 percent. $^{24}$

Under these assumptions, a lower bound on the IRR (in real terms) is positive and moderate at 3.2 percent per annum, which is somewhat higher than current real interest rates in Uruguay. As this is a highly conservative lower bound given all of the plausible benefits that are excluded, this exercise suggests that the child investments made through PANES may indeed be an attractive public policy in Uruguay. Needless to say, this remains a highly speculative calculation in the absence of actual earnings data.

\section{Conclusion}

This paper studies the impact of a social assistance program on the incidence of low birthweight in Uruguay, an upper middle income Latin American country. The program consisted principally of a cash transfer that was targeted to households in the bottom decile of the income distribution, a

\footnotetext{
${ }^{23}$ The source of the per capita income data is the World Development Indicators database (http://data.worldbank.org/country/uruguay). Note that this is arguably a conservative assumption given Uruguay's much faster growth rates in the recent past.

${ }^{24}$ We are not aware of any Uruguay-specific deadweight loss estimates but a recent paper estimates that the marginal cost of public funds in other developing countries is on the order of 17\% (Auriol and Warlters 2012).
} 
population with an incidence of low birthweight of around 10 percent, similar to rates found among poor populations in the U.S.

The analysis shows that the program led to a considerable reduction in low birthweight incidence. Using a unique matched micro-dataset with vital statistics, program, hospital and social security records, our estimates imply a fall in the incidence of low birthweight on the order of 15 percent, allowing beneficiaries to entirely close the baseline gap in low birthweight incidence with the ineligible program applicants. The estimated impacts are similar using three distinct econometric approaches: a difference-in-differences estimator, a mother fixed effects specification, and a regression discontinuity design that exploits an eligibility threshold in the program's design. A back-of the envelope internal rate of return calculation suggests that it could be an attractive public policy option.

We also explore the mechanisms behind these effects. Many different channels hypothesized in the literature appear to contribute to the overall reduction in low birthweight, including improved maternal nutrition and reduced smoking. While there is an increase in prenatal visits, it appears too small to explain much of the birthweight effect. Although we find some evidence of minor offsetting household labor supply responses (most likely induced in part by the means-tested nature of the program), we show that PANES receipt increased eligible mothers' total net household income by at least 25 percent. The modest reduction in mother's work hours during pregnancy, with the associated reduction in stress, may have contributed to the birthweight result. There was also a marked reduction in out-of-wedlock births among program beneficiaries, which may have further reduced maternal stress and positively affected birth outcomes.

Taken together, our results imply that cash social assistance may help to break the cycle of intergenerational poverty by improving child health. The offsetting behavioral effects that could in theory limit the benefits of such transfers (e.g., increased drinking or smoking, or family break-up) appear to be of second-order importance in our setting. The findings appear relevant not just for Latin American countries but also to wealthier societies given Uruguay's generally good infant health measures (which are similar to those observed in poor populations in the U.S.), and the nearly universal access to prenatal care in the country. 


\section{References}

Aizer, A. (2010), "Poverty, Violence and Health: The Impact of Domestic Violence during Pregnancy on Newborn Health", mimeo, Brown University.

Aizer, A., J. Currie and E. Moretti (2007), "Does Managed Care Hurt Health? Evidence from Medicaid Mothers", Review of Economics and Statistics, vol. 89(3): 385-399, 04.

Aizer, A., L. Stroud and S. Buka (2009), "Maternal Stress and Child Well-Being: Evidence from Siblings", mimeo, Brown University.

Alexander, G. and Korenbrot C. (1995), "The role of prenatal care in preventing low birthweight". The Future of Children 5: 103-120.

Almond, D., K. Chay and D. Lee (2005), “The Costs of Low Birthweight”, Quarterly Journal of Economics, 120(3): 1031-1083.

Almond, D. and J. Currie (2011a), "Human Capital Development before Age Five”, in Handbook of Labor Economics (D. Card and O. Ashenfelter ed.s), Vol. 4.

Almond, D. and J. Currie (2011b), "Killing Me Softly: The Fetal Origins Hypothesis", mimeo, Columbia University.

Almond, D. H. W. Hoynes and D. Schanzenbach (2011a), "Inside the war on poverty: 'The impact of food stamps on birth outcomes", Review of Economics and Statistics, 93 (2): 387-403.

Almond, D. H. W. Hoynes and D. Schanzenbach (2011b), "Childhood Exposure to the Food Stamp Program: Long-run Health and Economic Outcomes", mimeo, Columbia University.

Almond, D. and B. Mazumder (2011), "Health Capital and the Prenatal Environment: The Effect of Ramadan Observance during Pregnancy", American Economic Journal: Applied Economics, forthcoming.

Amarante, V., R. Arim and A. Vigorito (2005), Criterios de selección de la población beneficiaria del PANES, report prepared for MIDES, Montevideo.

Amarante, V., G. Burdín, M. Manacorda and A. Vigorito (2008), Informe de evaluación intermedia del PANES, report prepared for MIDES, Montevideo.

Amarante, V., M. Ferrando, M. Manacorda, A. Vernengo and A. Vigorito (2009), Informe final de evaluación del PANES. Report prepared for MIDES, Montevideo.

Ashenfelter, O. (1978), "Estimating the Effect of Training Programs on Earnings", Review of Economics and Statistics, 60, 47-57.

Auriol, E. and M. Warlters (2012), "The Marginal Cost of Public Funds and Tax Reform in Africa", Journal of Development Economics, vol. 97, n. 1, 58-72.

Baland, J.M and J Robinson (2000), “Is Child Labor Inefficient?”, Journal of Political Economy, 108(4), 663-679.

Banerjee, A. and S. Mullainathan (2010), "The Shape of Temptation: Implications for the Economic Lives of the Poor", mimeo, MIT.

Barber, S. and P. Gertler (2008), "Empowering women: how Mexico's conditional cash transfer program raised prenatal care quality and birthweight", mimeo, U.C. Berkeley.

Barker, D.J.P. (1990), “The fetal and infant origins of adult disease”, British Medical Journal, 301(6761): 1111.

Becker, G. (1960), “An Economic Analysis of Fertility”, in Demographic and Economic Change in Developed Countries. Princeton, NJ: NBER.

Becker, G. S. and H. G. Lewis, (1973), "On the Interaction between the Quantity and Quality of Children”, Journal of Political Economy, 81(2), S279-S288.

Behrman, J. and M. Rosenzweig (2004), "Returns to Birthweight", Review of Economics and Statistics, 86(2): 586-601. 
Bitler M.P, J. B. Gelbach, H.W. Hoynes, and M. Zavodny (2004), “The Impact of Welfare Reform on Marriage and Divorce", Demography, 41(2): 213-236.

Bitler, M. and Currie, J. (2004), "Does WIC Work? The Effect of WIC on Pregnancy and Birth Outcomes", Journal of Policy Analysis and Management, 23, 73-91.

Black, S., P. Devereux, and K. Salvanes (2007), "From the cradle to the labor market? The effect of birthweight on adult outcomes", Quarterly Journal of Economics, 122(1): 409-439.

Black, S., and P. Devereux. (2011). "Recent Developments in Intergenerational Mobility", Handbook of Labor Economics, Vol. 4, Part B.

Bozzoli, C. and C., Quintana-Domeque (2010), “The Weight of the Crisis: Evidence from Newborns in Argentina", mimeo, University of Alicante.

Case, A. (2000), "Health, Income and Economic Development”, mimeo, Princeton University.

Case, A., A. Fertig and C. Paxson (2005), "The lasting impact of childhood health and circumstances", Journal of Health Economics, 24, 365-389.

Case, A., D. Lubotsky and C. Paxson (2005), "Economic Status and Health in Childhood: The Origins of the Gradient", American Economic Review, 92(5), 1308-1334

Cabella, W. and Peri A. (2005), El sistema de estadísticas vitales en Uruguay: elementos para su diagnóstico y propuestas para su mejoramiento. Report prepared for the project 'Mejoramiento del Sistema Estadístico Nacional', convenio Facultad de Ciencias SocialesInstituto Nacional de Estadística, Montevideo, Uruguay.

Camacho, A. (2008), "Stress and Birth Weight: Evidence from Terrorist Attacks", American Economic Review Papers and Proceedings, 98(2), 511-515.

Card, D. (1999), "The causal effect of education on earnings", in Handbook of Labor Economics (D. Card and O. Ashenfelter ed.s), Vol. 3.

Card, David, and Daniel Sullivan (1988), "Measuring the Effect of Subsidized Training Programs on Movements In and Out of Employment", Econometrica, 56(3), 497-530.

Clausson, B., P. Lichtenstein S. and Cnattingius (2000), "Genetic influence on birthweight and gestational length determined by studies in offspring of twins", International Journal of Obstetrics \& Gynaecology. 107(3, March): 375-381.

Conley, D. and N. Bennett (2000), "Is biology destiny? Birthweight and life chances", American Sociological Review 65: 458-467.

Conley, D. and N. Bennett (2001), "Birth Weight and Income: Interactions across Generations", Journal of Health and Social Behavior, 42 (December): 450-465.

Currie, J. (2009), "Healthy, wealthy and wise: socioeconomic status, poor health in childhood and human capital development", Journal of Economic Literature, 47: 87-122.

Currie, J. and N. Cole (1993), "Welfare and child health: the link between AFDC participation and birthweight", American Economic Review, 86(4): 971-985.

Currie, J. and J. Gruber (1996), "Saving Babies: The Efficacy and Cost of Recent Changes in the Medicaid Eligibility of Pregnant Women”, Journal of Political Economy, 104(61), 12631296.

Currie, J. and R. Hyson (1999), "Is the Impact of Health Shocks Cushioned by Socioeconomic Status? The Case of Low Birthweight", American Economic Review, 89(2): 245-250.

Currie, J. and E. Moretti (2003), "Mother's Education and the Intergenerational Transmission of Human Capital: Evidence from College Openings", Quarterly Journal of Economics, 118(4): 1495-1532

Currie, J. and E. Moretti (2007), "Biology as Destiny? Short and Long-Run Determinants of Intergenerational Transmission of Birthweight”, Journal of Labor Economics, 25:231-264. 
Currie, J. and E. Moretti (2008), "Did the Introduction of Food Stamps Affect Birth Outcomes in California?”, in Making Americans Healthier, (Schoeni, House, Kaplan, and Pollack eds.), Russell Sage Foundation.

Currie, J., M. Neidell and J. Schmeider (2009), “Air Pollution and Infant Health: Lessons from New Jersey", Journal of Health Economics, 28(3, May), 688-703.

Currie, J. and J. F. Schmieder (2009), "Air Pollution and Health around the World. Fetal Exposures to Toxic Releases and Infant Health", American Economic Review: Papers \& Proceedings 299 (2): 177-183.

Currie, J. and R. Walker (2010), “Traffic Congestion and Infant Health: Evidence from E-Z Pass”, mimeo, Columbia University.

Currie, J. and F. Gahvari (2008), "Transfers in Cash and In-Kind: Theory Meets the Data”, Journal of Economic Literature, 46 (2), 333-383.

Dehejia, R., and A. Lleras-Muney (2004), “Booms, Busts, and Babies’ Health”, Quarterly Journal of Economics, 119(3), 1091-1130.

Del Bono, E., J. Ermisch and M. Francesconi (2008), "Intrafamily resource allocations: a dynamic model of birthweight". IZA Discussion Papers, 3704.

Duryea, S., A. Olgiati and L. Stone (2006), "Registro inexacto de nacimientos en América Latina”, RES Working Papers, 4444, Inter-American Development Bank, Research Department. Washington DC.

Fescina R., Butrón R., De Mucio B., Martínez G., Diaz-Roselló JL., Simini F., Camacho and Mainero L (2007). Sistema de Informatico Perinatal. Historia clínica perinatal: instructivo de llenado y clarificación de términos . CLAP/SMR 1563. Pan American Health Organization, Latin American Centre of Perinatology and Women Health.

Fiszbein, A. and N. Schady (2009), Conditional Cash Transfers: Reducing Present and Future Poverty, World Bank Publications.

Heckman, J. (1995), “Lessons from the Bell curve”, Journal of Political Economy, 103(51), 10511120.

Heckman, J. (2000), "Policies to foster human capital”, Research in Economics, 54(1), 3-56.

Hoynes, H. W. (1996), "Welfare Transfers in Two-Parent Families: Labor Supply and Welfare Participation Under the AFDC-UP Program”, Econometrica, 64(2), 295-332.

Hoynes, H. W., D. L. Miller and D. Simon (2011), "Income, the Earned Income Tax Credit, and Infant Health", mimeo, U.C. Davis.

Hoynes, H. W., M. Page, and A Huff Stevens (2011), "Can targeted transfers improve birth outcomes? Evidence from the introduction of the WIC program", Journal of Public Economics, 95: 813-827.

Hoynes, H. W. and D. Schanzenbach (2009), "Consumption Responses to In-Kind Transfers: Evidence from the Introduction of the Food Stamp Program", American Economic Journal: Applied Economics, 1(4), 109-139.

Hoynes, H. W. and D. Schanzenbach (2011), "Work Incentives and the Food Stamp Program", Journal of Public Economics, forthcoming.

Instituto Nacional de Estadística (2009), Las Estadísticas Vitales, Montevideo, Uruguay.

Jewell, T. and Triunfo P. (2007), "El peso al nacer de los niños de la principal maternidad del Uruguay: 1995-2004." Desarrollo y Sociedad, No 59, March, Universidad de los Andes

Kramer, M.S. (1987), "Determinants of low birthweight: methodological assessment and metaanalysis”, Bulletin World Health Organization, 65(5): 663-737. 
Manacorda M., E. Miguel E. and A. Vigorito (2011), "Government Transfers and Political Support”, American Economic Journal: Applied Economics, 3(3): 1-28.

Matijasevich, A., C. Barros, J.L. Díaz-Rosselló, E. Bergel and C. Forteza (2004), "Factores de riesgo para muy bajo peso al nacer y peso al nacer entre 1.500-2.499 gramos. Un estudio del sector público de Montevideo, Uruguay”, Archivos Pediatricos Uruguayos, 75(1): 2635.

Murtaugh, M. and J. Weingart (1995), "Individual Nutrient Effects on Length of Gestation and Pregnancy Outcome”. Seminars in Perinatology. 19 (3), 197-210

McCrary, J. (2008), "Manipulation of the running variable in the regression discontinuity design: A density test", Journal of Econometrics, 142(2), 698-714.

McCrary, J. and H. Royer (2010), "The Effect of Female Education on Fertility and Infant Health: Evidence from School Entry Policies Using Exact Date of Birth”, Quarterly Journal of Economics, forthcoming.

Miguel, Edward, and Michael Kremer. (2004). "Worms: Identifying Impacts on Education and Health in the Presence of Treatment Externalities", Econometrica, 72(1), 159-217.

Ministerio de Salud Publica (2011), Estadísticas Vitales, Montevideo, Uruguay.

Moffitt, R. (1998), "The Effect of Welfare on Marriage and Fertility", in Welfare, the Family, and Reproductive Behavior (R. Moffitt ed.). Washington, DC: National Academy Press, 50-97.

Moffitt, R. (2002), "Welfare Programs and Labor Supply", in Handbook of Public Economics (A. J. Auerbach and M. Feldstein eds.)

Nichols, A. (2011), rd 2.0: Revised Stata module for regression, Statistical Software Components S456888, Boston College.

Royer, H. (2009), "Separated at Girth: US Twin Estimates of the Effects of Birthweight." American Economic Journal: Applied Economics, 1(1): 49-85.

Stecklov, G., P. Winters, J. Todd and F. Regalia (2006), "Demographic Externalities from Poverty Programs in Developing Countries: Experimental Evidence from Latin America", American University Working Papers Series, 2006-1.

UNDP (2005), Informe Nacional de Desarollo Humano. Montevideo, Uruguay.

UNICEF (2004), Low Birthweight. Country, Regional and Global Estimates, New York.

Udry, C. (2004), "Child Labor”, mimeo, Yale University.

U.S. Bureau of the Census (2010), Income, Poverty, and Health Insurance Coverage in the United States. 2009. Current Population Report. U.S. Department of Commerce, Economics and Statistics Administration.

United Nations Children's Fund (2009), Global database on low birthweight.

World Bank (2011), World Development indicators. The World Bank, Washington.

World Health Organization (2009), World Health Statistics, Geneva.

World Health Organization (2010), World Health Statistics, Geneva. 
Figure 1: Timing of PANES program activities and data collection

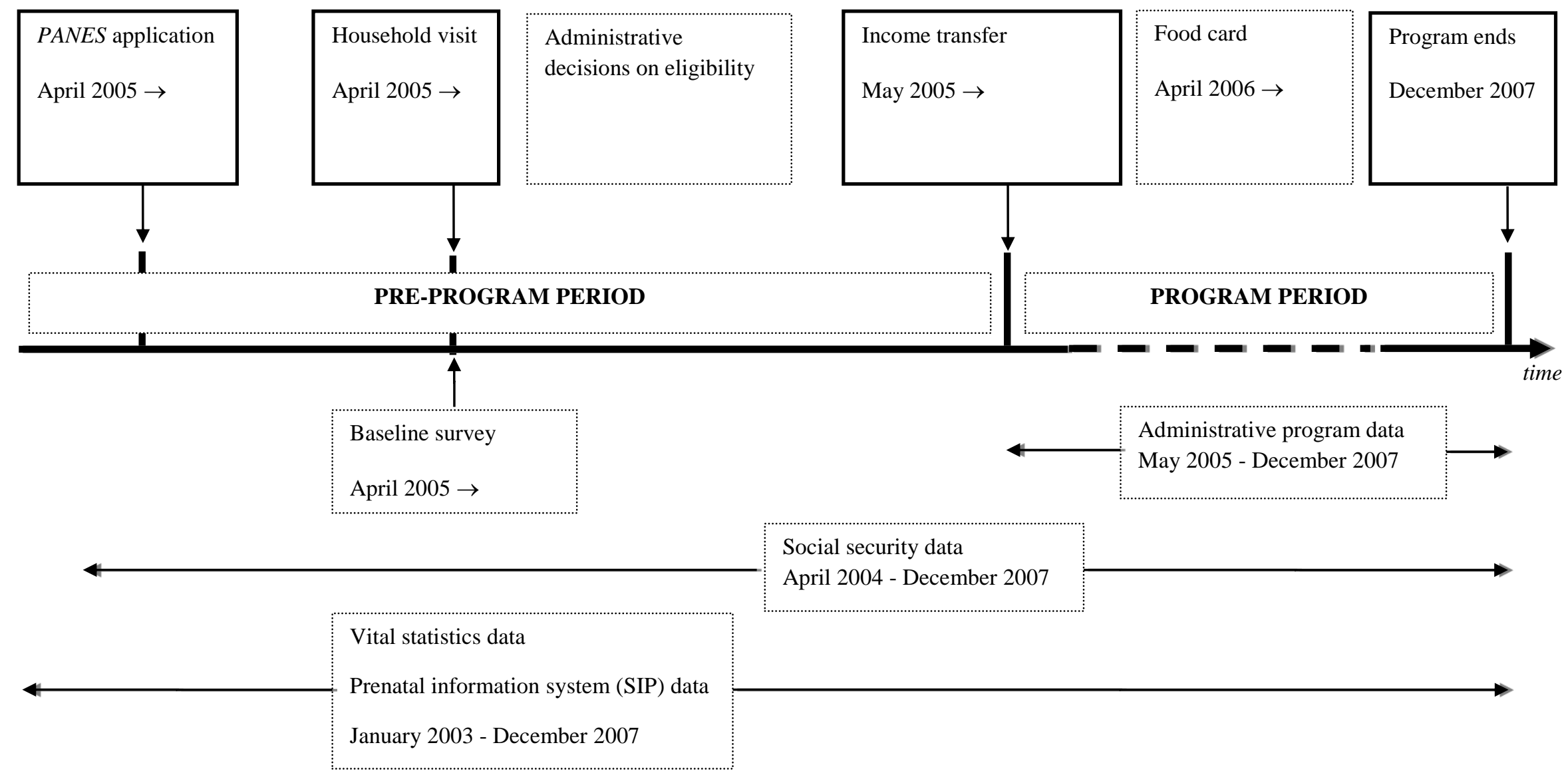


Figure 2: Fraction of low birthweight and treated births as a function of time to/since first income transfer

A: Y-axis: Low birthweight

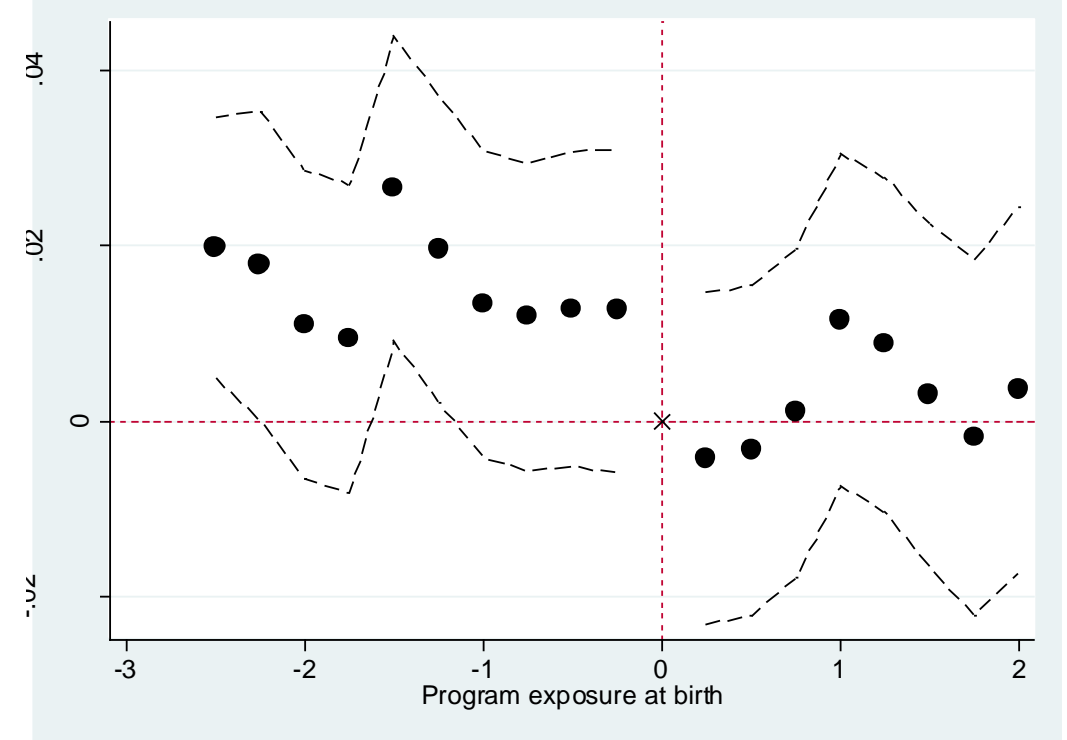

B: Y-axis: Treated $(0 / 1)$

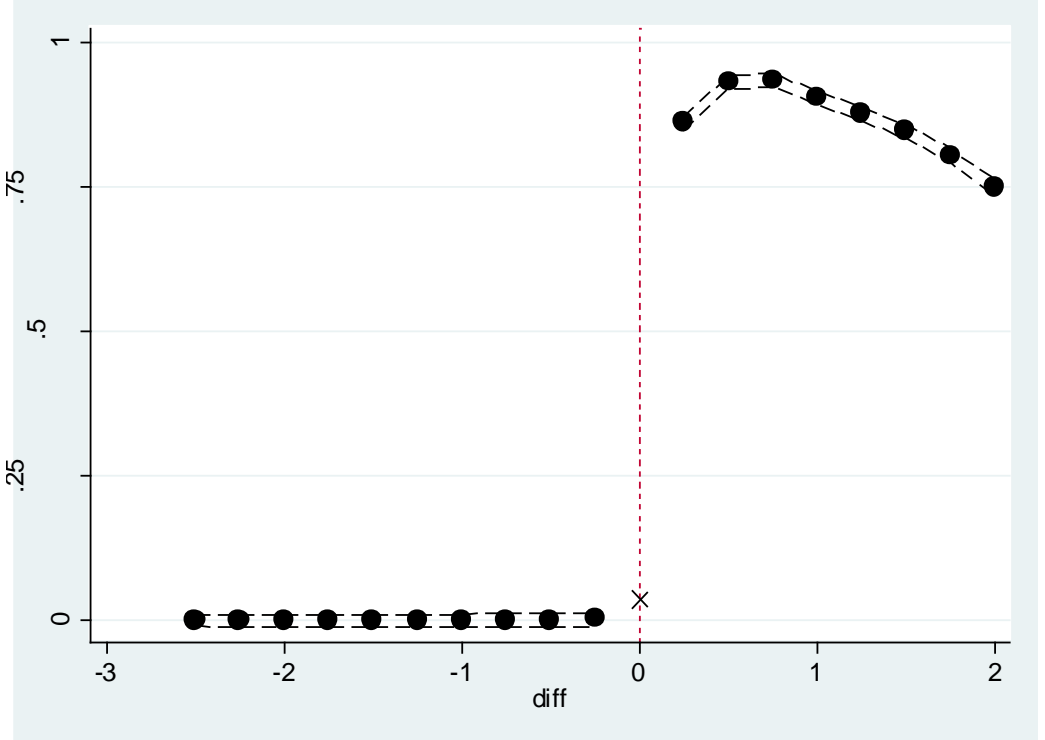

Notes. Panel A reports the fraction of low weight births as a function of the difference between the time of birth and the time of first payment of the cash transfer (for PANES eligible mothers only). Data are expressed as differences with respect to positive program exposure in utero of less than a full trimester (denoted by a vertical line). Dotted lines denote 95 percent confidence intervals. Panel B reports a similar graph where the variable on the vertical axis is the fraction of births with at least one day of PANES program exposure in the first two trimesters of pregnancy. 
Figure 3: Estimated proportional program effects by birthweight

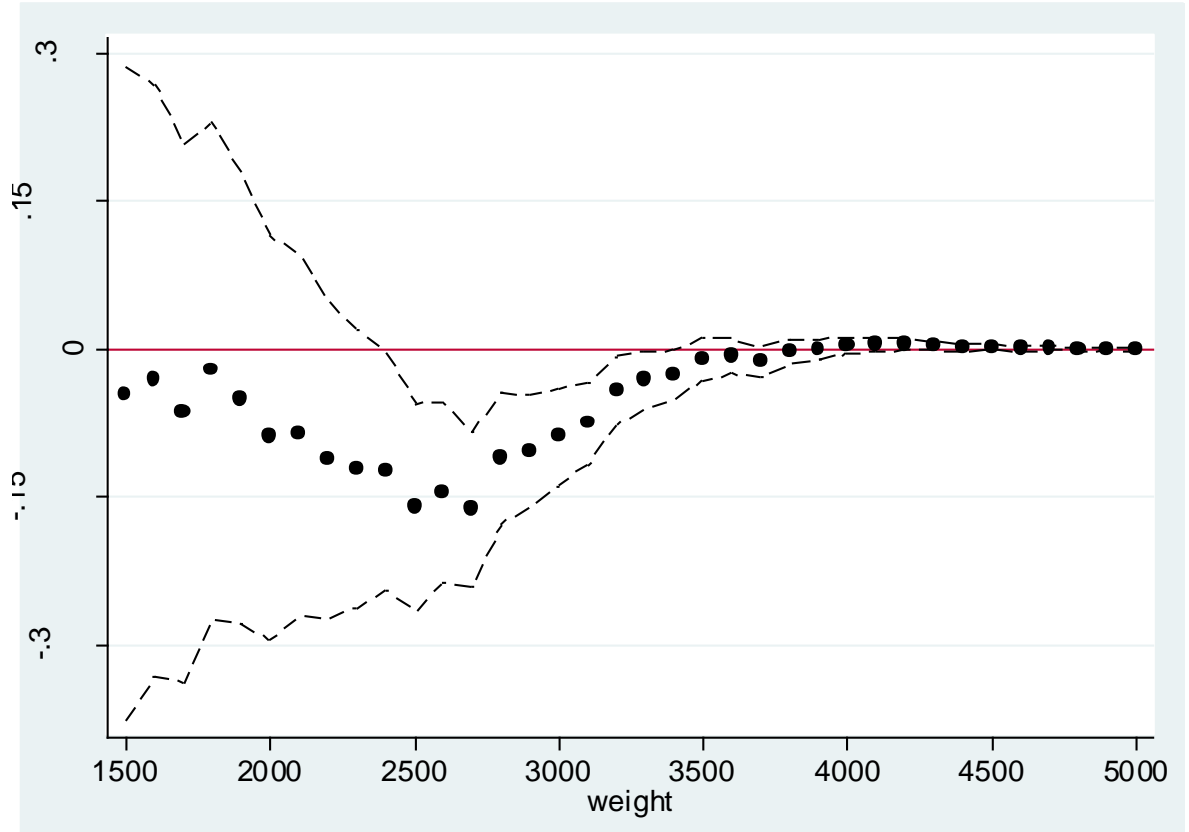

Notes. The figure reports the estimated percentage change in the probability of being below each level of birthweight as a result of treatment. Each point comes from a separate 2SLS regression including controls (as in column 2 of Table 2). 95 percent confidence intervals around the estimates also reported. See also notes to Table 2. 
Figure 4: Proportion of low birthweight and treated births as a function of the predicted income score

A: Low birthweight, program period

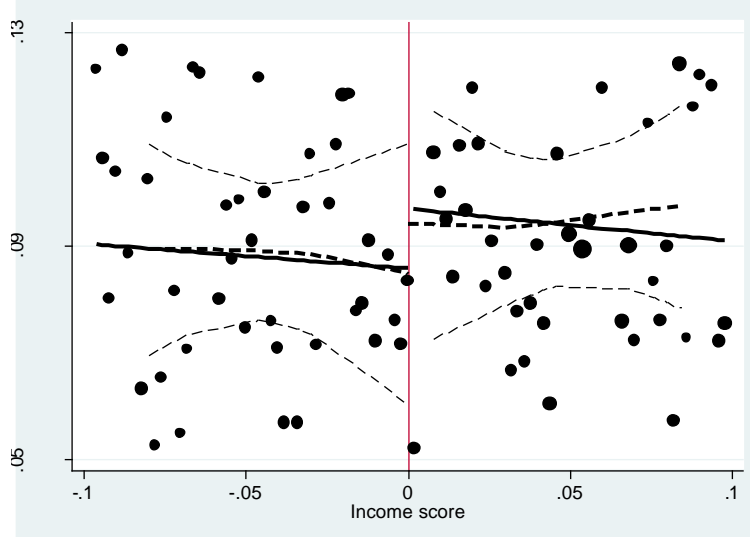

B: Low birthweight, pre-program period

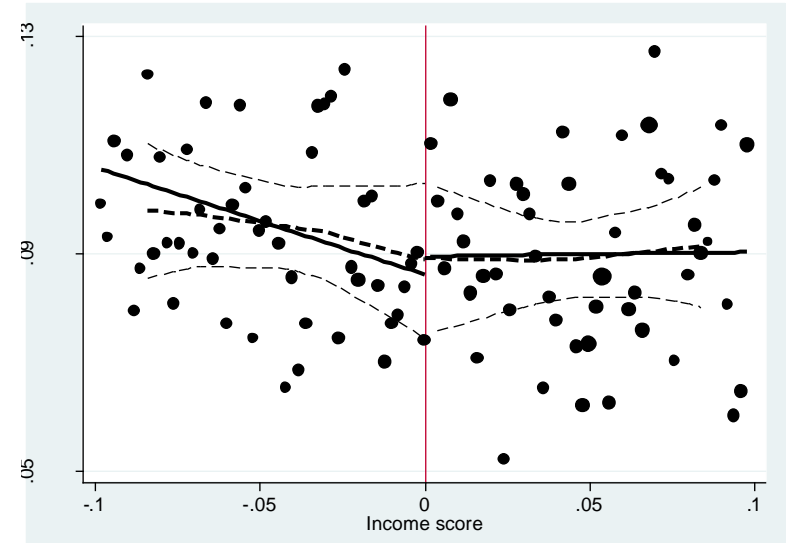

C: Treated

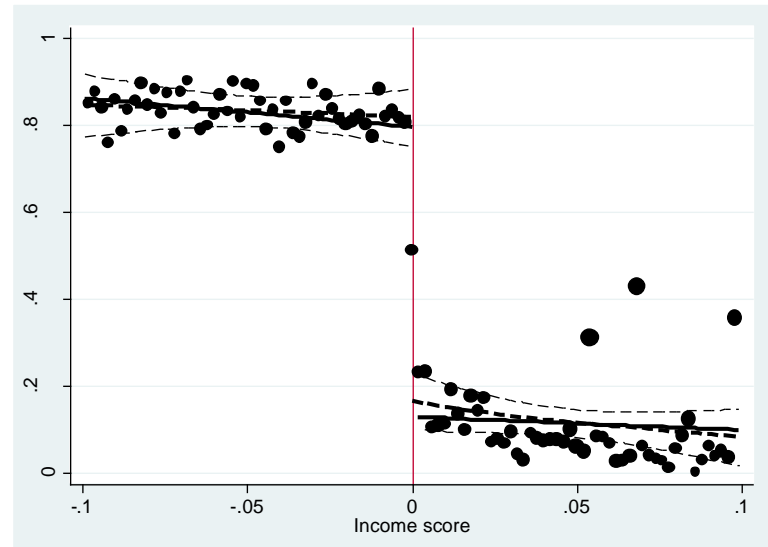

Notes. Panel A reports the proportion of low weight births among PANES applicant mothers as a function of the normalized income score during the program period (see text for details). A vertical line corresponds to PANES the eligibility threshold at a normalized predicted income score of zero. The figure also reports two estimated curves on either side of the threshold: a linear polynomial in the income score (solid line) and local linear regression (dashed line) computed using the Stata command "rd" with optimal bandwidth (Nichols 2011), as well as the 95\% confidence intervals around the estimated linear prediction (thin dotted lines). Panels B and C report similar graphs where the variables on the vertical axis are, respectively, the proportion of low weight births in the pre-program period, and the fraction on mothers in receipt of the income transfer during the first two trimesters of pregnancy (during the program period). The size of the points in these figures is proportional to the number of observations in that cell. 
Figure 5: Fertility rates as a function of time to/since the baseline visit, difference between PANES eligible and ineligible women

A: Actual fertility difference

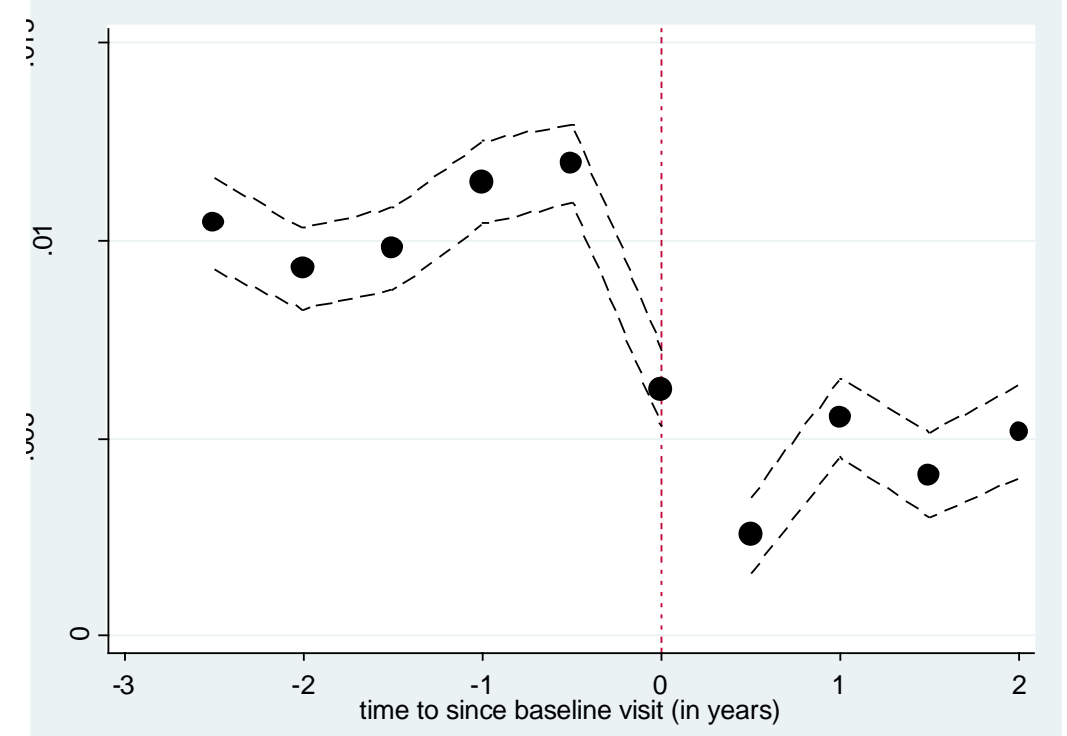

B: Adjusted fertility difference

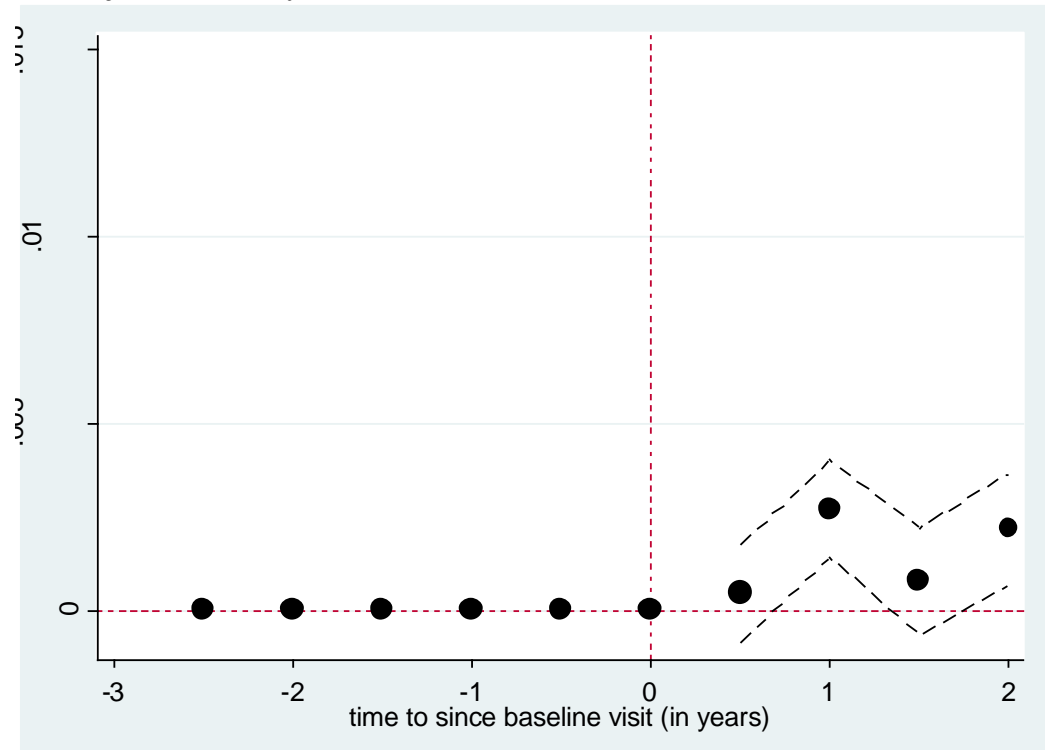

Notes. Panel A reports the difference in fertility rates between eligible and ineligible PANES applicant women of child bearing age as a function of the time to and since the baseline survey. Panel B reports the same difference reweighted by the fraction of eligible mothers in each cell defined by mother's fertility history, age and education measured in the baseline survey. See text for details. Dotted lines are the $95 \%$ confidence interval. 
Table 1: Descriptive statistics, all births in Uruguay (2003-2007)

\begin{tabular}{|c|c|c|c|}
\hline & PANE & plicants & Non-applicants \\
\hline & $\begin{array}{c}\text { Eligible } \\
\text { (1) }\end{array}$ & $\begin{array}{c}\text { Ineligible } \\
\text { (2) }\end{array}$ & (3) \\
\hline Pre-program period (January 2003 - March 200 & & & \\
\hline Panel A: Birth outcomes & & & \\
\hline 1. Low birthweight & 0.102 & 0.093 & 0.084 \\
\hline 2. Birthweight (g) & 3141.05 & 3161.35 & 3217.92 \\
\hline 3. Gestational length & 38.50 & 38.50 & 38.56 \\
\hline Panel B: Prenatal and natal care & & & \\
\hline 4. Total number of prenatal visits & 6.53 & 7.53 & 8.28 \\
\hline 5. Week of first prenatal visit & 17.50 & 16.24 & 14.16 \\
\hline 6. Number of visits, first trimester & 0.31 & 0.40 & 0.63 \\
\hline 7. Number of visits, second trimester & 1.61 & 1.92 & 2.19 \\
\hline 8. Number of visits, third trimester & 4.61 & 5.22 & 5.46 \\
\hline Panel C: Socio-economic indicators & & & \\
\hline 9. Average birthweight area of residence & 3193.53 & 3196.20 & 3200.88 \\
\hline 10. Average birthweight health center & 3170.43 & 3185.76 & 3207.59 \\
\hline 11. Public health center delivery & 0.77 & 0.55 & 0.33 \\
\hline 12. Birth delivery paid by private health insurance & 0.06 & 0.14 & 0.43 \\
\hline 13. Mother incomplete primary education & 0.12 & 0.05 & 0.04 \\
\hline 14. Number of previous pregnancies & 2.37 & 1.44 & 1.26 \\
\hline 15. Out-of-wedlock birth & 0.80 & 0.72 & 0.52 \\
\hline 16. Missing child father information & 0.61 & 0.51 & 0.31 \\
\hline 17. Father incomplete primary education & 0.10 & 0.04 & 0.02 \\
\hline 18. Mother works & 0.12 & 0.18 & 0.43 \\
\hline 19. Mother earnings during pregnancy ${ }^{ \pm}$ & 107.29 & 283.68 & - \\
\hline 20. Household earnings during pregnancy ${ }^{ \pm}$ & 591.85 & 1669.11 & - \\
\hline 21. Household benefits during pregnancy \pm & 521.65 & 807.75 & _ \\
\hline 22. Household total income during pregnancy ${ }^{ \pm}$ & 1113.50 & 2476.86 & - \\
\hline 23. Mother age & 25.43 & 24.78 & 27.50 \\
\hline 24. Father age & 30.77 & 29.62 & 31.93 \\
\hline 25. Birth assisted by doctor & 0.49 & 0.55 & 0.71 \\
\hline 26. Mother smoker in first trimester ${ }^{\wedge}$ & 0.31 & 0.25 & 0.16 \\
\hline 27. Mother weight (kg), first prenatal visit ${ }^{\wedge}$ & 56.36 & 60.18 & 61.81 \\
\hline 28. Mother weight $(\mathrm{kg})$, final prenatal visit & 63.26 & 68.48 & 71.20 \\
\hline Panel D: Program period (April 2005 - Decembe & & & \\
\hline 29. Low birthweight & 0.091 & 0.091 & 0.082 \\
\hline 30. Ever received income transfer & 0.97 & 0.11 & - \\
\hline 31. Income transfer during pregnancy $(0 / 1)$ & 0.55 & 0.06 & - \\
\hline 32. Amount of income transfer during pregnancy & 607.52 & 69.21 & - \\
\hline 33. Ever received food card & 0.80 & 0.12 & - \\
\hline 34. Food card during pregnancy $(0 / 1)$ & 0.33 & 0.04 & - \\
\hline 35. Amount of food card during pregnancy & 134.45 & 12.06 & - \\
\hline 36. Mother earnings during pregnancy ${ }^{ \pm}$ & 132.81 & 340.96 & - \\
\hline 37. Household earnings during pregnancy ${ }^{ \pm}$ & 808.28 & 1979.12 & - \\
\hline 38. Household benefits during pregnancy ${ }^{ \pm}$ & 683.46 & 874.04 & - \\
\hline 39. Household total income during pregnancy ${ }^{ \pm}$ & 2233.80 & 2934.43 & - \\
\hline & & 20,872 & \\
\hline Observations, SIP sample & 15,093 & 6,905 & 57,477 \\
\hline
\end{tabular}

Notes. The table reports means for three groups of individuals: PANES eligible (column 1), ineligible (column 2), and the rest of the Uruguayan population (non-PANES applicants, column 3). Pre-program period (Panels A, B and C) refers to births occurring between January 2003 and March 2005, while program period (panel D) refers to births occurring between April 2005 and December 2007. ${ }^{ \pm}$: data available only since March 2004. The earnings and transfers variables are in monthly terms. ${ }^{\wedge}$ data available only for SIP sample. 
Table 2: PANES program effects on birth outcomes, 2SLS estimates

\begin{tabular}{|c|c|c|}
\hline \multirow{2}{*}{\multicolumn{3}{|c|}{$\begin{array}{l}\text { Dependent variable: } \\
\text { Panel A: 2SLS }\end{array}$}} \\
\hline & & \\
\hline 1. Low birthweight & $\begin{array}{c}-0.015^{* * *} \\
(0.005)\end{array}$ & $\begin{array}{l}-0.017 * * * \\
(0.005)\end{array}$ \\
\hline 2. Birthweight & $\begin{array}{r}23.774^{* *} \\
(10.440)\end{array}$ & $\begin{array}{l}29.721 * * * \\
(9.871)\end{array}$ \\
\hline 3. Gestational length (in weeks) & $\begin{array}{c}0.077^{* *} \\
(0.038)\end{array}$ & $\begin{array}{c}0.084^{* *} \\
(0.037)\end{array}$ \\
\hline 4. Premature birth & $\begin{array}{l}-0.007 \\
(0.006)\end{array}$ & $\begin{array}{l}-0.008 \\
(0.005)\end{array}$ \\
\hline 5. In bottom decile of weight per gestational length & $\begin{array}{c}-0.016^{* * *} \\
(0.006)\end{array}$ & $\begin{array}{c}-0.017 * * * \\
(0.005)\end{array}$ \\
\hline \multicolumn{3}{|l|}{$\begin{array}{l}\text { Panel B: Reduced form and first stage results } \\
\text { 6. Low birthweight, by length of exposure - reduced form }\end{array}$} \\
\hline Entered $3^{\text {rd }}$ trimester & $\begin{array}{l}-0.011 \\
(0.008)\end{array}$ & $\begin{array}{l}-0.007 \\
(0.007)\end{array}$ \\
\hline Entered $2^{\text {nd }}$ trimester & $\begin{array}{c}-0.022^{* * *} \\
(0.007)\end{array}$ & $\begin{array}{c}-0.020^{* *} \\
(0.007)\end{array}$ \\
\hline Entered $1^{\text {st }}$ trimester & $\begin{array}{c}-0.026 * * * \\
(0.007)\end{array}$ & $\begin{array}{c}-0.024 * * * \\
(0.007)\end{array}$ \\
\hline Entered before conception & $\begin{array}{l}-0.008 \\
(0.005)\end{array}$ & $\begin{array}{c}-0.010 * * \\
(0.005)\end{array}$ \\
\hline 7. Low birthweight - reduced form & $\begin{array}{l}-0.013^{* * *} \\
(0.005)\end{array}$ & $\begin{array}{c}-0.014 * * * \\
(0.004)\end{array}$ \\
\hline 8. Income transfer during pregnancy $(0 / 1)$ - first stage & $\begin{array}{c}0.864^{* * *} \\
(0.005)\end{array}$ & $\begin{array}{c}0.867^{* * *} \\
(0.005) \\
\end{array}$ \\
\hline Controls & No & Yes \\
\hline
\end{tabular}

Notes. Number of observations: 68,858. Each cell refers to a separate regression. Entries in the panel A are estimated coefficients from a 2SLS regression of each dependent variable on an indicator for receipt of the income transfer during the first two trimesters since conception, where receipt of the transfer is instrumented by an indicator for mother eligibility for PANES during pregnancy (see text for details). Row 5 reports the probability of being in the bottom decile of the weight distribution conditional on gestational length. Row 6 reports coefficients form an OLS regression of low birthweight (as in row 8) on indicators for in utero exposure of less than one full trimester, one full trimester, two full trimesters, three full trimesters, and before conception. Rows 7 and 8 report the reduced form and first stage estimates, respectively. All regressions control for month of conception indicators, indicators for month of entry into the program (which takes on a value of zero for ineligible individuals) and an indicator for the PANES income score being below the eligibility threshold. Controls in column (2) include indicators for mother's age and education, sex of the child, an indicator for multiple pregnancies (e.g., twins), for the number of previous pregnancies, month of the baseline survey visit, and month of program enrollment. Standard errors clustered by mother. ***, **, *: significant at 99, 95 and $90 \%$ level. 
1. Mother fixed effects (FE) estimates

2. Eligible mothers only

Regression discontinuity (RD) estimates

3. All observations

4. Predicted income score range $(-0.1,0.1)$

5. Predicted income score range $(-0.1,0.1)$, linear polynomial

6. Fixed time of first payment (independent of actual entry date)

7. Among non-premature births

8. Pre-food card period only

9. With controls for food card roll-out

10. Among pregnancies initiated before first payment

11. Among births within one year from baseline

By subgroup:

12. Teen mothers

13. Non-teen mothers

14.Married mother

15. Single mother

16. Smaller households (three or fewer household members)

17. Larger households (at least four household members)
Coefficient estimate (s.e.)

Obs.

$$
\begin{gathered}
-0.018^{* *} \\
(0.009)
\end{gathered}
$$

$-0.016^{* *}$

$(0.003)$

$-0.013^{* *}$

$(0.006)$

$-0.014^{*}$

$(0.008)$

$-0.014$

$(0.018)$

$-0.020 * *$

(0.008)

$-0.009 * *$

$-0.017^{* *}$

(0.008)

$-0.022 * * *$

(0.007)

$-0.019 * *$

(0.008)

$-0.012 *$

(0.007)

$-0.029 * *$

(0.013)

$-0.016^{* *}$

(0.005)

$-0.028 * *$

(0.012)

$-0.013^{* *}$

(0.006)

-0.018 *

(0.010)

$-0.018 * * *$

(0.006)
24,346

48,891

20,675

9,529

9,529

68,858

55,621

50,953

68,858

37,054

54,250

13,986

54,872

12,231

56,627

19,593

49,265

Notes: 2SLS estimates of the effect of PANES participation on low birthweight, in a specification equivalent to Table 2, column (2). Row 1 includes mother fixed effects. Row 2 restricts to program eligible mothers only. Rows 3 to 5 present regression discontinuity estimates on program period data only. Row 3 uses a broad neighborhood around the eligibility threshold, while rows 4 and 5 restrict to predicted income scores in the narrow range -0.1 to +0.1 . Row 5 additionally includes a linear polynomial in the income score interacted with an eligibility indicator. Row 6 defines as eligible all pregnancies starting after January 2005 to mothers with an income score below the eligibility threshold. Row 7 restricts to non-premature births (38 weeks or more). Row 8 restricts to children conceived before November 2005, who were either in the $3^{\text {rd }}$ trimester or already born when the food card was introduced. Row 9 includes an indicator for receipt of the food card during the first two trimesters of pregnancy, instrumented by an indicator of eligibility, and also controls for month of first food card payment. Row 10 restricts to pregnancies that started before the date of first program payment. Row 11 restricts to pregnancies concluded within one year from baseline. Rows 12 through 17 report results by subgroups (using baseline marital status and household size). See also notes to Table 2. 
Table 4: PANES program effects on additional outcomes, 2SLS estimates

Dependent variable:

\section{Panel A: Socio-economic indicators during pregnancy}

Coefficient estimate (s.e.)

Obs.

1. Value of income transfer during pregnancy

2. Value of Food Card during pregnancy

$1040 * * *$

(5)

$191^{* * *}$

(2)

3. Other household government benefits during pregnancy ${ }^{ \pm}$

4. Mother formal sector earnings during pregnancy ${ }^{ \pm}$

5. Household formal sector earnings during pregnancy ${ }^{ \pm}$

6. Mother works during pregnancy

7. Household total income during pregnancy ${ }^{ \pm}$

8. Average birthweight in area of residence (g)

Panel B: Prenatal and delivery care

9. Total number of prenatal visits

10. Number of prenatal visits, first trimester

11. Number of prenatal visits, second trimester

12. Number of prenatal visits, third trimester

13. Week of first prenatal visit

14. Birth assisted by medical personnel

15. Public hospital delivery

16. Average pre-PANES birthweight in health center (g)

Panel C: Prenatal maternal health information (SIP dataset)

17. Maternal health data in SIP dataset

18. Mother weight, kg (conditional on week of pregnancy), first weighing visit (avg: week 16)

19. Mother weight, kg (conditional on week of pregnancy), final weighing visit (avg: week 35)

20. Mother smoked during first trimester of pregnancy

Panel D: Marital status and paternity

21. Out-of-wedlock birth

22. Missing child father information

\section{Panel E: Fertility}

23. All births

24. Births within one year from baseline
$-15$

$-40 * * *$

(15)

$-175^{* * *}$

(047)

$-0.013^{* *}$

(0.006)

$968 * * *$

(55)

1.080

$0.144^{* *}$

(0.059)

$-0.025 *$

(0.013)

0.049

(0.024)

$0.132 * * *$

(0.045)

$-0.061$

(0.134)

$-0.002$

(0.009)

$-0.009$

(0.008)

1.461

(1.301)

0.003

(0.007)

0511

(0.384)

0.966**

(0.406)

$-0.032 * *$

(0.015)

$-0.021 * * *$

(0.007)

$-0.016 *$

(0.009)

$0.0013^{* * *}$

(0.0003)

0.0002

(0.0005)
(0.729)
68,858

68,858

39,870

39,870

39,870

68,858

39,870

65,541

67,863

67,883

67,877

67,875

63,721

68,858

68,450

68,855

68,858

21,374

21,374

21,374

68,763

68,858

$1,037,793$

377,562

Notes. 2SLS estimates of the effect of PANES participation on various dependent variables, in a specification equivalent to Table 2, column (2). Regressions in rows 18 and 19 additionally control for the week of first and last visit, respectively. ${ }^{ \pm}$: data available only since March 2004. See also notes to Tables 1 and 2. 


\section{SUPPLEMENTARY ONLINE APPENDIX - NOT INTENDED FOR PUBLICATION}

Appendix A: Additional tables and figures

\begin{tabular}{|c|c|c|c|c|c|}
\hline Country/Region & $\begin{array}{l}\text { Low birth } \\
\text { weight, } \\
\%^{(a)}\end{array}$ & $\begin{array}{c}\text { Infant } \\
\text { mortality rate } \\
\text { (per 1000) }^{(\mathrm{b})}\end{array}$ & $\begin{array}{l}\text { Births assisted } \\
\text { by health } \\
\text { personnel, \%(c) }\end{array}$ & $\begin{array}{c}\text { At least one } \\
\text { prenatal visit, } \\
\%^{\left({ }^{(}\right)}\end{array}$ & $\begin{array}{l}\text { Per capita GDP } \\
\text { (PPP US\$) }^{(\mathrm{d})}\end{array}$ \\
\hline Uruguay & 8 & 11 & 99 & 97 & 13,189 \\
\hline United States & 8 & 7 & 99 & 99 & 45,989 \\
\hline Latin America/Caribbean & 9 & 19 & 96 & 95 & 10,575 \\
\hline
\end{tabular}

Notes:

(a) Source: United Nations Children's Fund (2009) and Ministerio de Salud Publica (2011) for Uruguay. The column reports the fraction of low weight births defined as children weighting less than $2.5 \mathrm{~kg}$ per 100 births.

(b) Source: Pan American Health Organization, reported in World Health Organization (2009). The column reports the probability of dying between birth and one year per 1,000 births.

(c) Source: World Health Organization (2011).

(d) Source: World Bank (2011). The column reports PPP-adjusted GDP per capita in US\$. 
A: Application

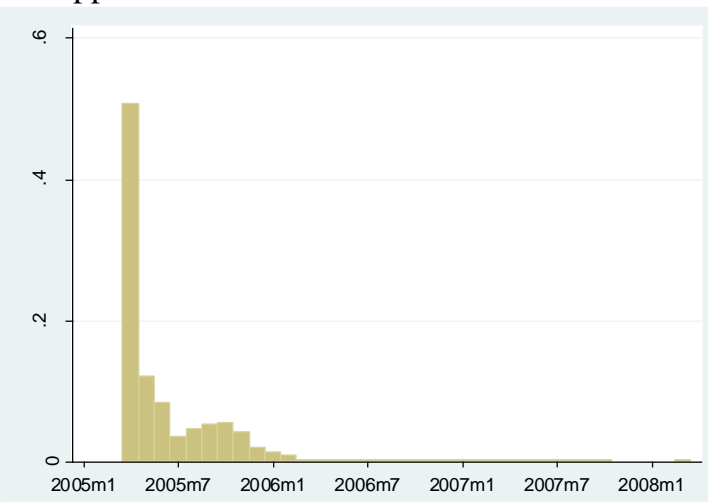

D: First payment of food card

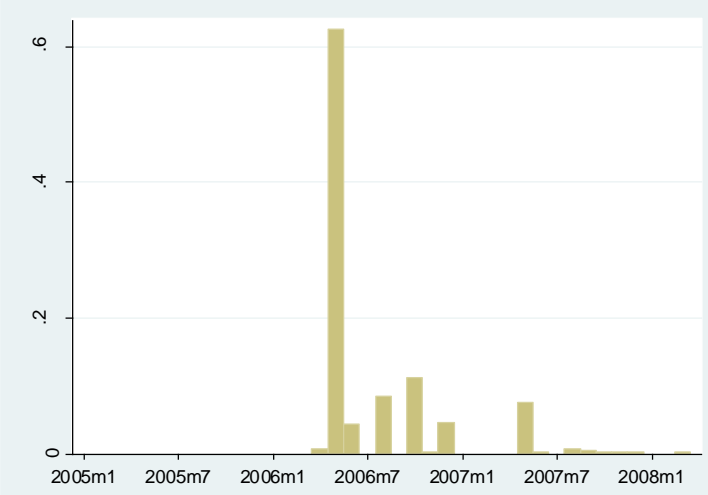

Appendix Figure A1: The timing of PANES program milestones

B: Baseline survey

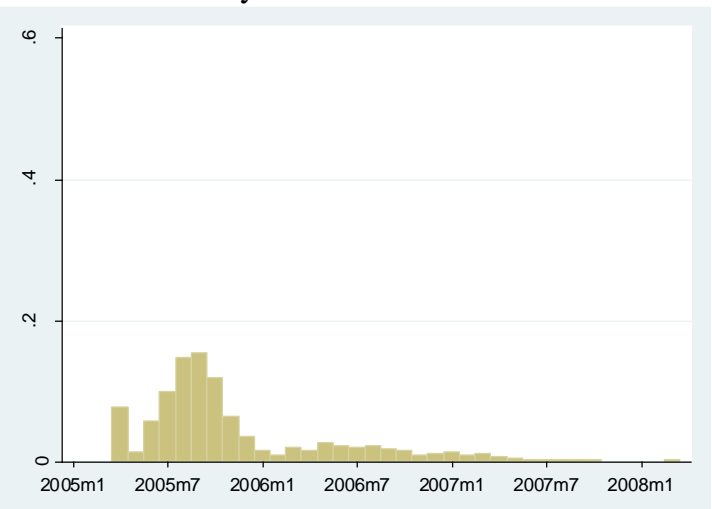

E: Baseline survey-Application (months)

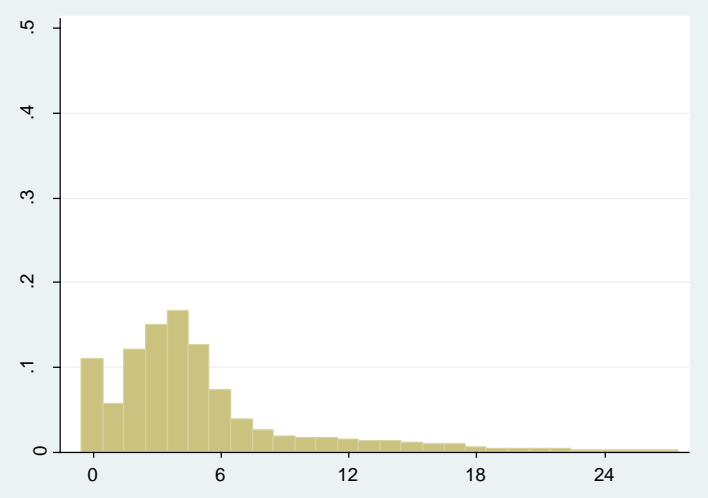

$\mathrm{C}$ : First income transfer payment

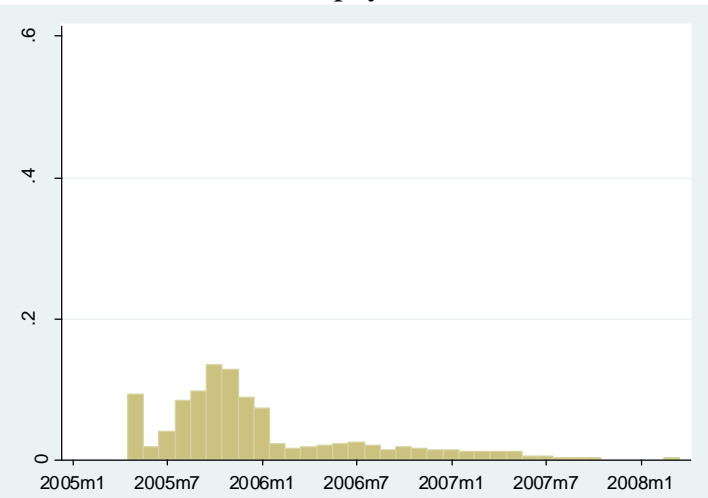

F: First income transfer-Baseline survey (months)

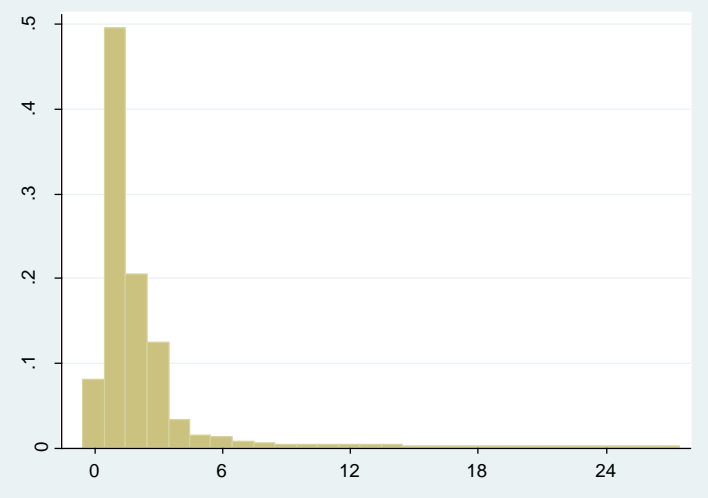

Notes. The figure reports the distribution of key program dates: application date (A), date of baseline survey (B), date of first payment of income transfer (C), date of first payment of the food card (D). Panels E reports the distribution of the differences between the variables in panels B and A, and Panel F reports the distribution of the differences between the variables in Panels C and B. 
Appendix Figure A2: Data integrity checks for the predicted income score (panel A) and birthweight (panel B)

Panel A: Distribution of the standardized PANES predicted income score, McCrary (2008) test

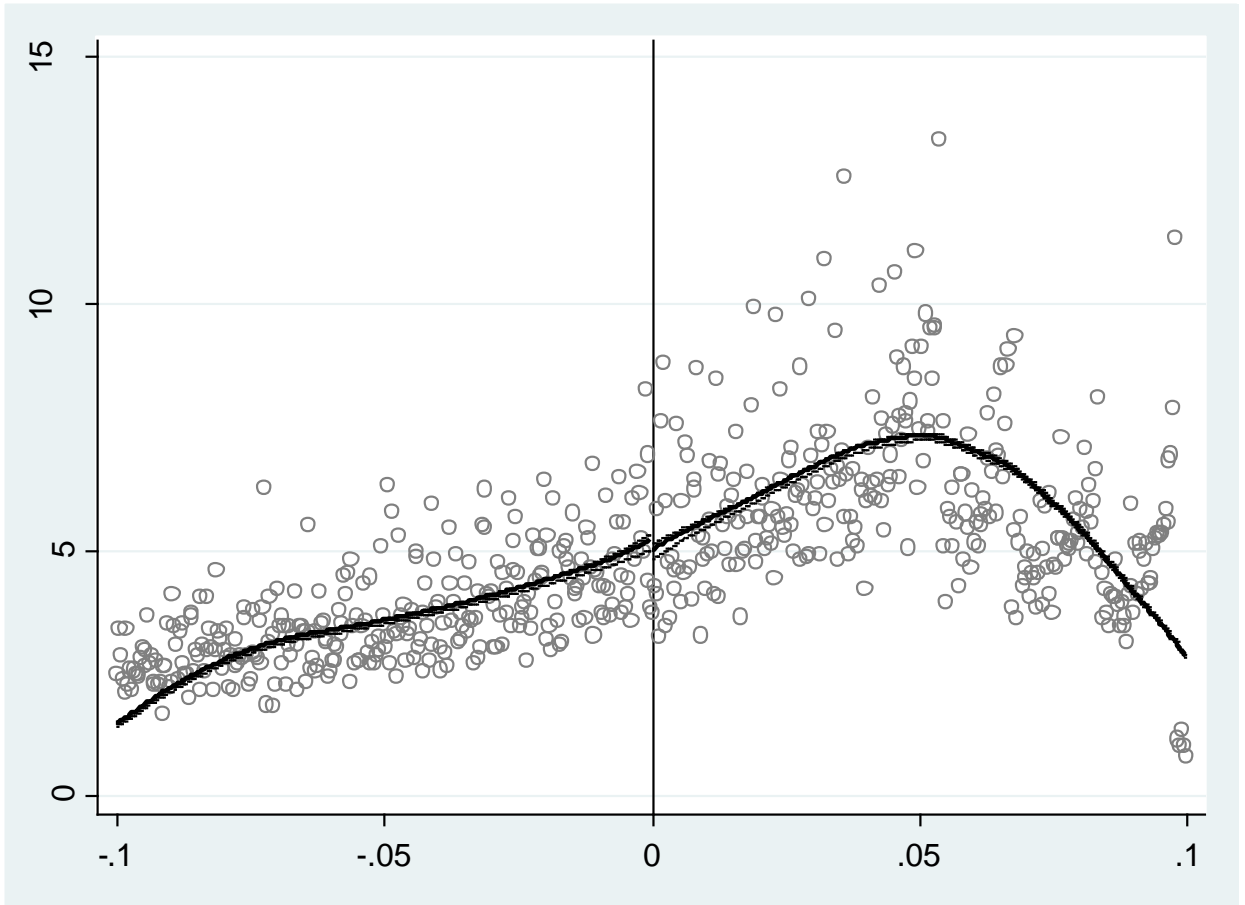

Panel B: Distribution of the birthweight measure (in grams)

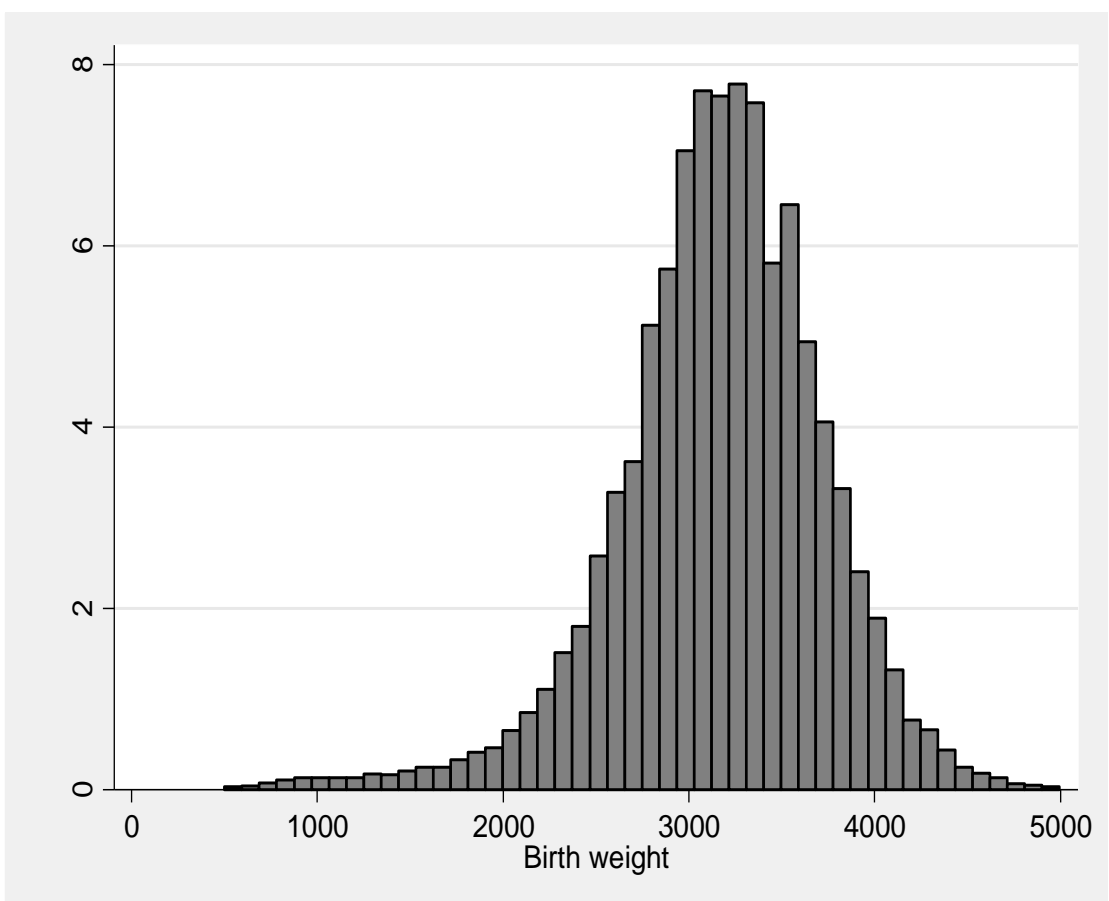

Notes. Panel A reports the frequency distribution of the income score and a smoothed kernel density estimator on either side of the threshold with the associated confidence interval. Panel B presents a histogram of birthweights in our sample, as recorded in the Uruguay vital statistics system data. 
Appendix Figure A3: Fertility rates and fraction treated as a function of time to/since key program dates

A: Fraction of children whose household was ever treated, as a function of date of birth relative to date of baseline survey visit

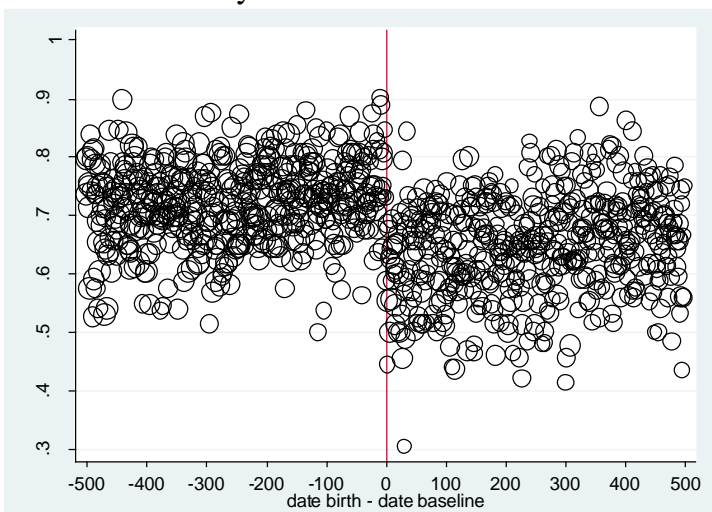

D: Fertilty rate as a function of time to/since baseline visit by PANES eligibility status - no children in the baseline survey

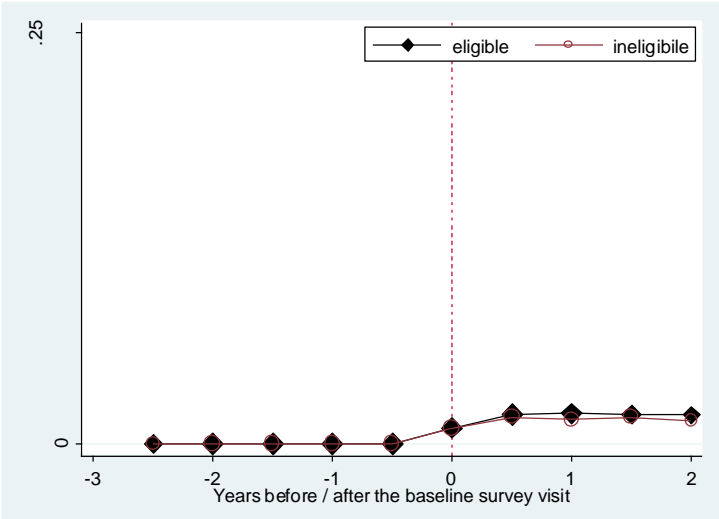

$B$ : Fertilty rate as a function of time to/since first income transfer

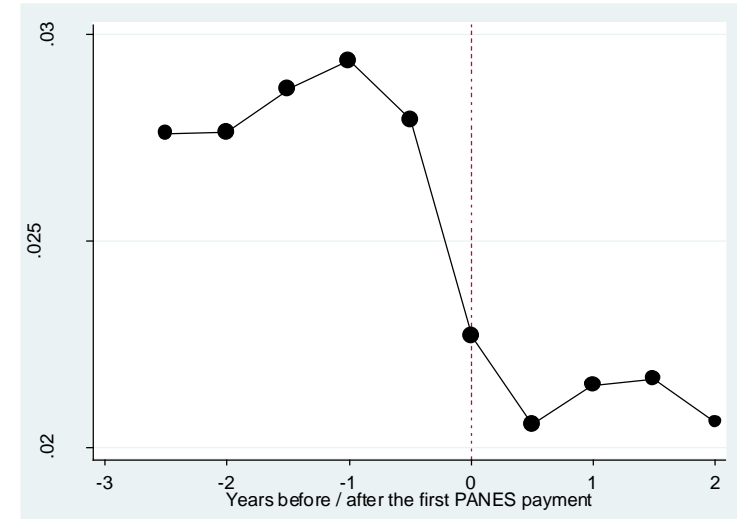

D: Fertilty rate as a function of time to/since baseline visit by PANES eligibility status - one child in the baseline survey

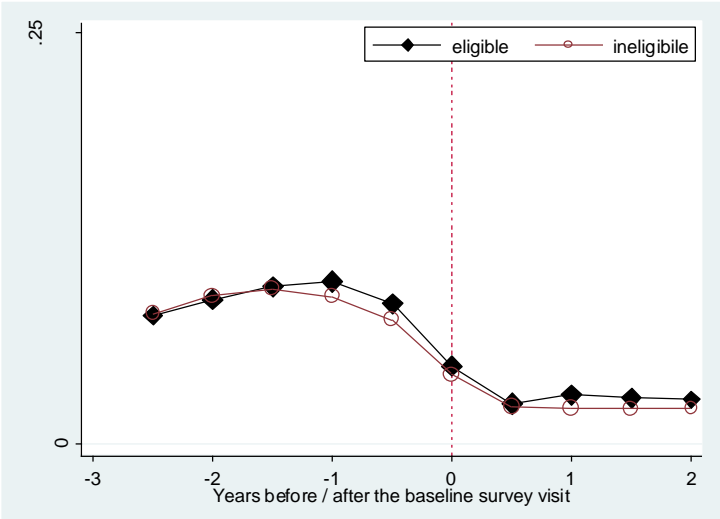

$C$ : Fertilty rate as a function of time to/since baseline visit, by PANES eligibility status

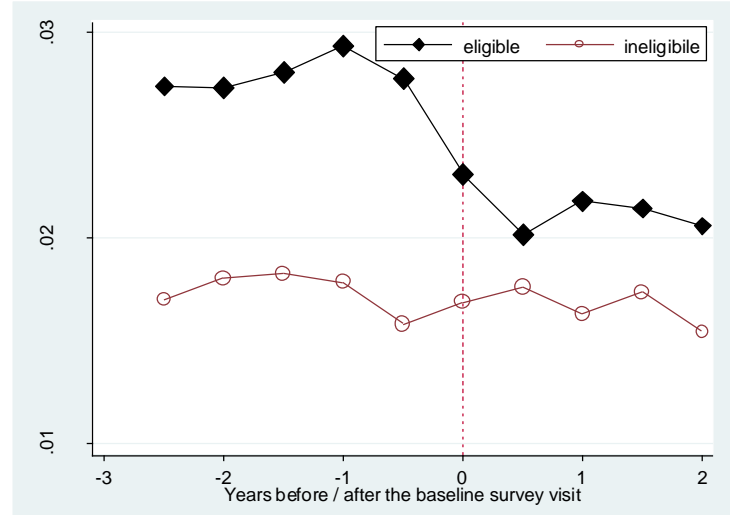

E: Fertilty rate as a function of time to/since baseline visit by PANES eligibility status - two or more children in the baseline survey

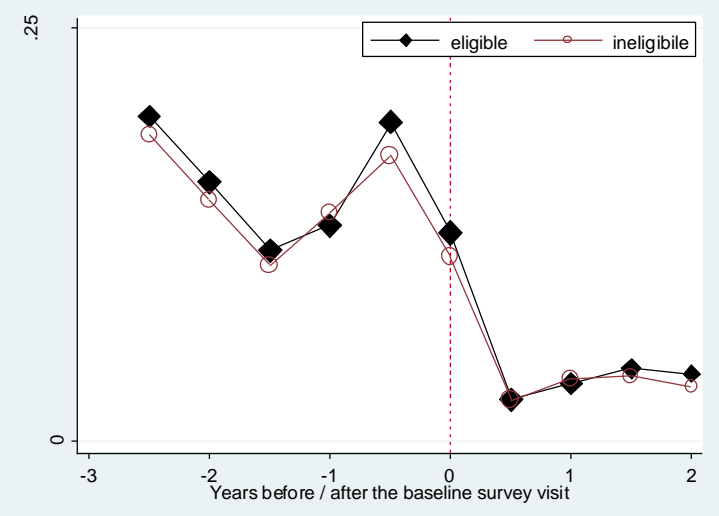

Notes. Panel A reports the proportion of children of applicant mothers whose household ever benefitted from the program as a function of the child's date of birth relative to date of the baseline survey. Panel B reports the proportion of PANES eligible mothers giving birth as a function of the time before/after the first payment. Panel C reports the fraction of PANES mothers giving birth as a function of the time before/after the baseline survey, separately for eligible and PANES ineligible women. Panels D, E and F report the same series as in Panel C separately by number of children born between January 2003 and the baseline survey. 


\section{Appendix B: PANES Program components}

The program also contained a variety of other minor components. Around 15\% of PANES households had one member attending training and educational activities organized by local NGOs (Rutas de Salida) with the aim of fostering social inclusion by recovering the lost work habits of participants, promoting knowledge of rights, strengthening social ties and, in some cases, promoting good health and nutrition practices. Around 16\% of PANES households had one member participating in a workfare program (Trabajo por Uruguay). Some participants were also incentivized to undergo routine medical checks (smear tests, prenatal visits and mammography for women and prostate exam for men) and were offered dental care and prostheses and eye surgery. Households in the treatment group received the monthly income provided they were not involved in public works employment (Trabajo por Uruguay), which paid a monthly salary of UY\$2,720 in lieu of the cash transfer. Participation in this employment scheme was voluntary and, among households who applied for jobs, participants were selected by lottery. In the paper we define program beneficiaries those receiving either the Ingreso Ciudadano (Citizen Income, the cash transfer) or Trabajo por Uruguay. As of spring 2007, nearly all eligible households declared having received the cash transfer at some point during the program, $71 \%$ reported having received the Food Card while only a minority (17.6\%) benefited from public works employment. Additional components of the PANES program included: regularization of beneficiaries' connection to public utilities networks (water and electricity) for a nominal fee, in-kind transfers of building materials for home improvements; health care including free dental and eye care (e.g., cataract surgery performed in Cuba) and prostheses; micro-finance loans and technical assistance for small entrepreneurial activities; and temporary accommodation for homeless households. Overall, around $13 \%$ of beneficiary households reported having received at least one of these additional components. PANES also encompassed schooling and health investments (additional school teachers in disadvantaged neighborhoods and public health investments). These affected beneficiary and non-beneficiary households equally. Although an Emergency health plan (Plan de Emergencia Sanitaria) was also originally conceived as an integral part of PANES, this was not de facto implemented. 